\title{
The Space of Inversion
}

Thesis by:

Matthew Alexander Zess

Thesis Supervisor:

Dr. Thomas Mical

A thesis submitted to the Faculty of Graduate Studies and Research in partial fulfillment of the requirements for the degree of

\section{Professional Masters of Architecture}

School of Architecture

Carleton University

Ottawa, Ontario

May 1, 2005

(C) Copyright 2005

Matthew A. Zess 


\section{$\underline{\text { Abstract }}$}

Objective and Universal "truths" have bombarded the individual into a Being that is forever in a state of self-concealment. The individual-self has expanded into a mass-Being, where things deemed "rational" and "reasoned" have fostered their existence as "positive values".

It is here that the idea of an architectural project as a mere 'means to ends' must be reconsidered. This thesis is an investigation of the individual's role in the making and the interpreting of architecture. I will prove that the only viable source for Truth and understanding is from within oneself. I will illustrate how such exterior-truths have a tendency to supersede subjective Truth by analyzing five modes of interpreting. These are; metaphor, narrative, apostrophe, language and intersubjectivity.

By giving priority to the 'act' or 'event' of architecture, I will allow for the experience of making and the experience of interpreting/viewing (the space of inversion) to be a purely-subjective, enduring and "passible" space. 


\section{$\underline{\text { Table of Contents }}$}

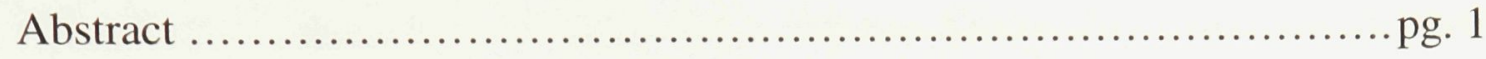

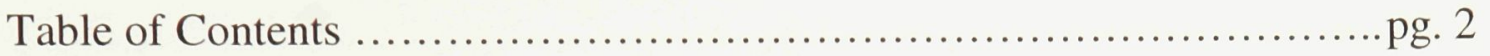

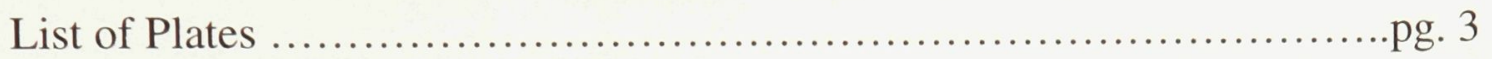

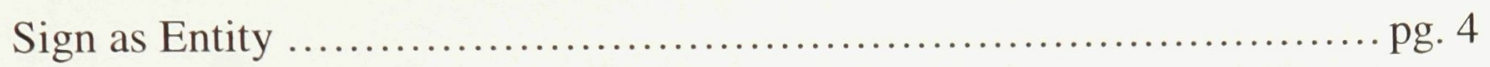

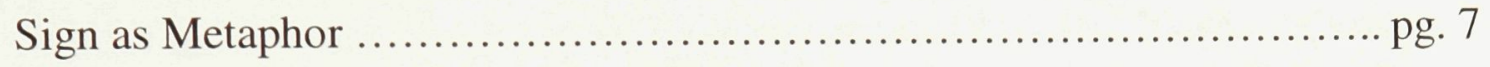

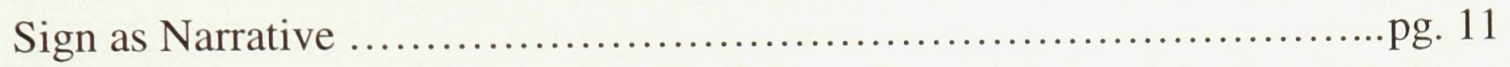

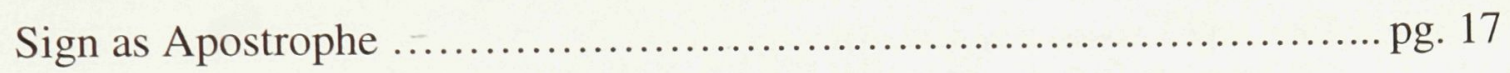

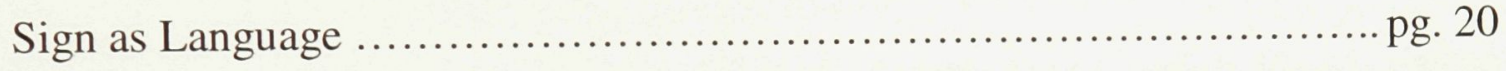

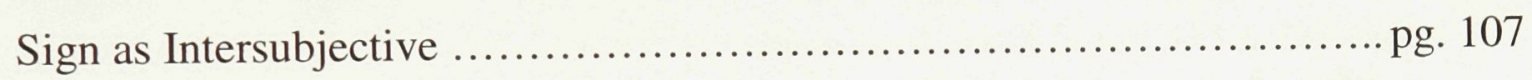


$\underline{\text { List of Plates }}$

Plates 1-4 pgs.5,6 Matt Zess. Sign as Entity: The 'end', the 'designed'. (4'-0" x 4'-0" x 4'-0"). 2004.

Plates 5-7 pgs.8,9,10 Matt Zess. Sign as Metaphor. (17"x 33”). 2004.

Plates 8-25 pgs.12 - 16 Matt Zess. Sign as Narrative. (11”x 17”). 2005.

Plates 26-28 pg. 45 Francis Bacon. Triptych May-June, 1973, oil on canvas (each panel $198 \times 147.5 \mathrm{~cm}$ ). Private Collection, Switzerland. Photo: Marlborough.

Plates 29-31 pg. $46 \quad$ Francis Bacon. Three Studies of Lucien Freud, 1969, oil on canvas (each panel $198 \times 147.5 \mathrm{~cm}$ ). Private collections. Photo: Marlborough.

Plate 32 pg. 58

Francis Bacon. Untitled (Crouching Nude on Rail), 1952, oil on canvas (each panel 193 x $137 \mathrm{~cm}$ ).

Private collection. Photo: Courtesy of Tony Shafrazi Gallery, New York.

Plate 33 gg. 89 Giuseppe Arcimbaldo. Earth, 1570, oil on canvas $(7.2 \times 48.7 \mathrm{~cm})$. Private collection. Photo: Ritter. 
Sign as Entity 


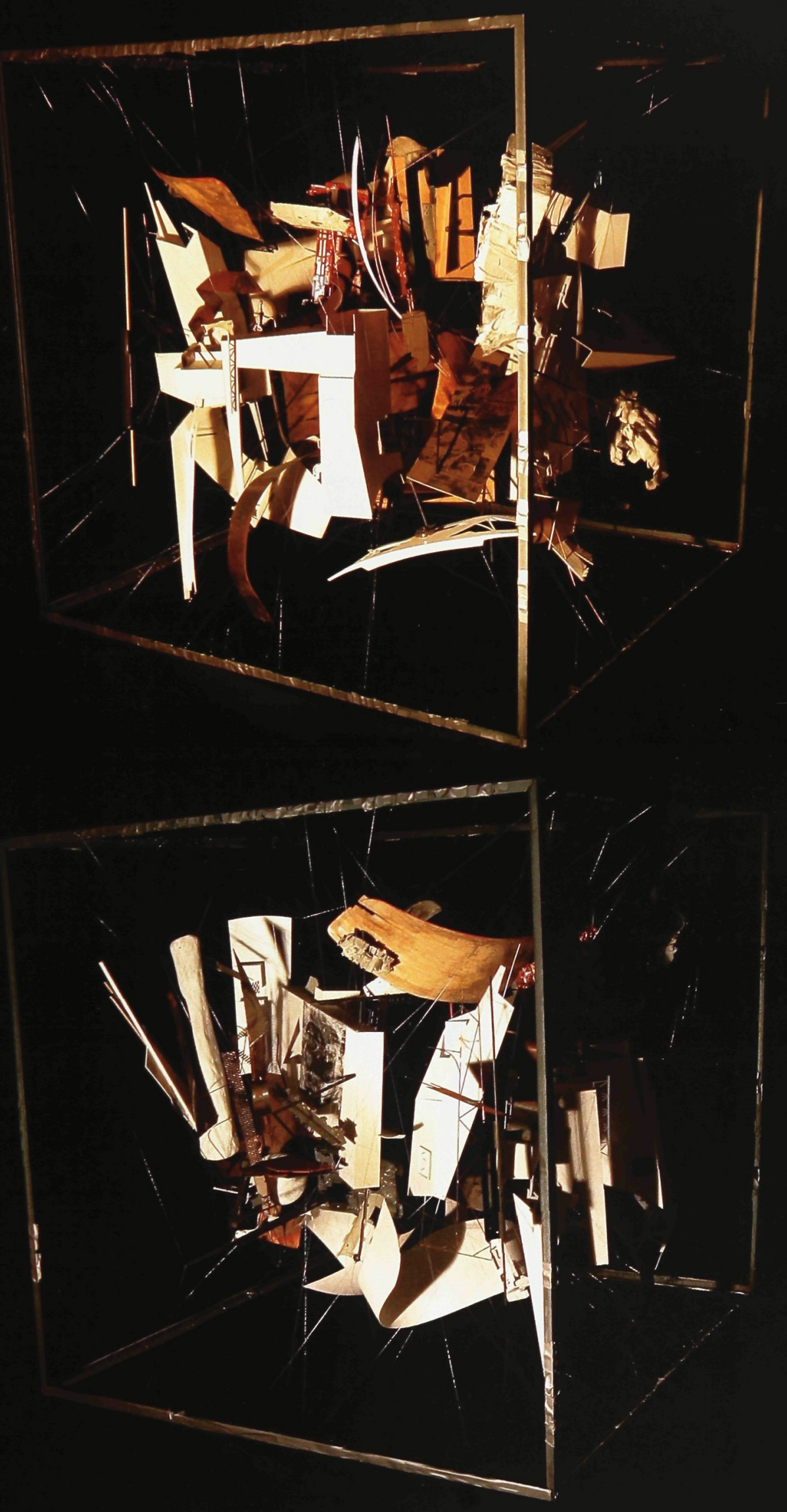

Plates 1 and 2

The 'end', the 'designed' 


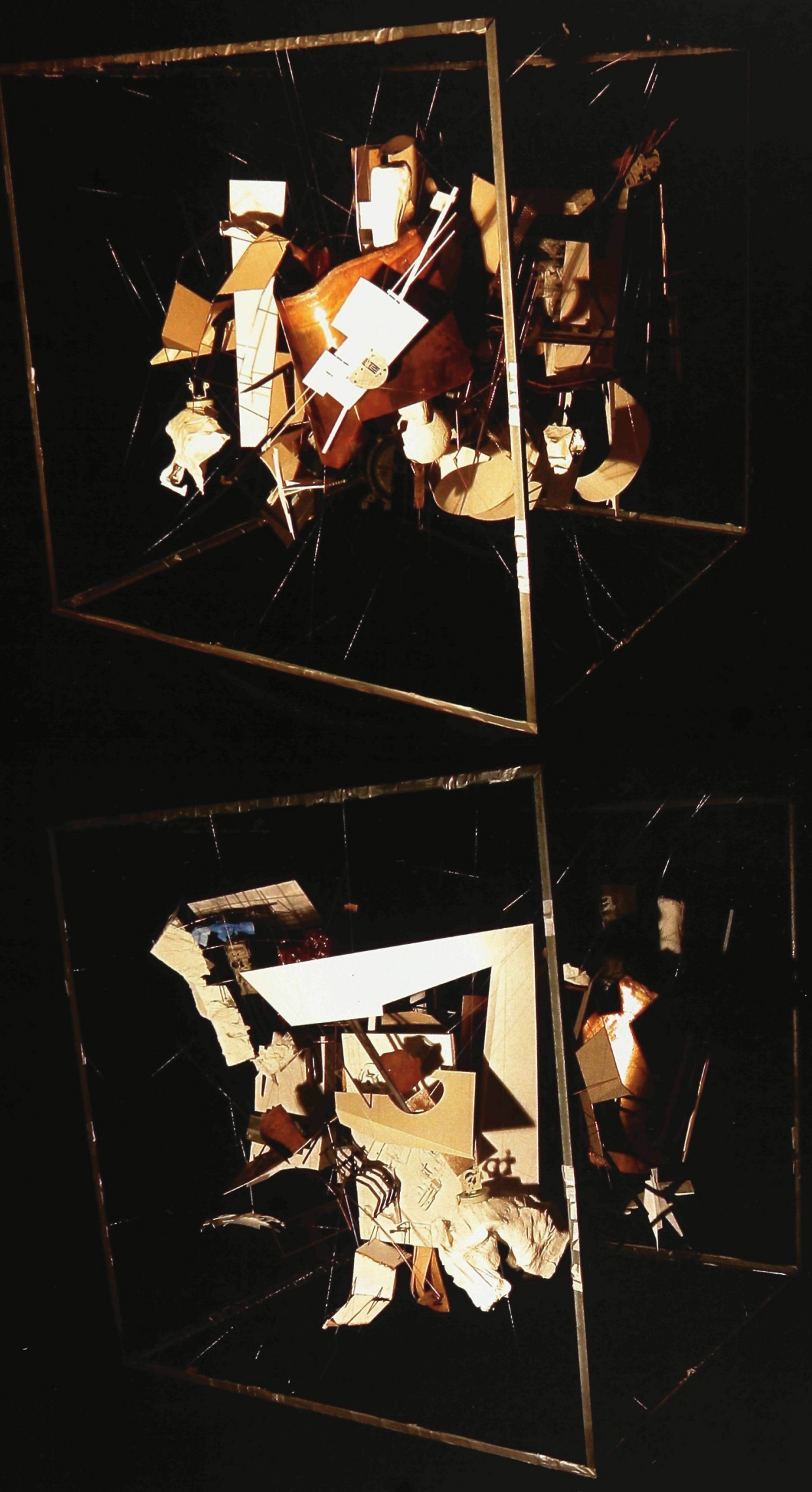

Plates 3 and 4

The 'end', the 'designed' 
Sign as Metaphor 


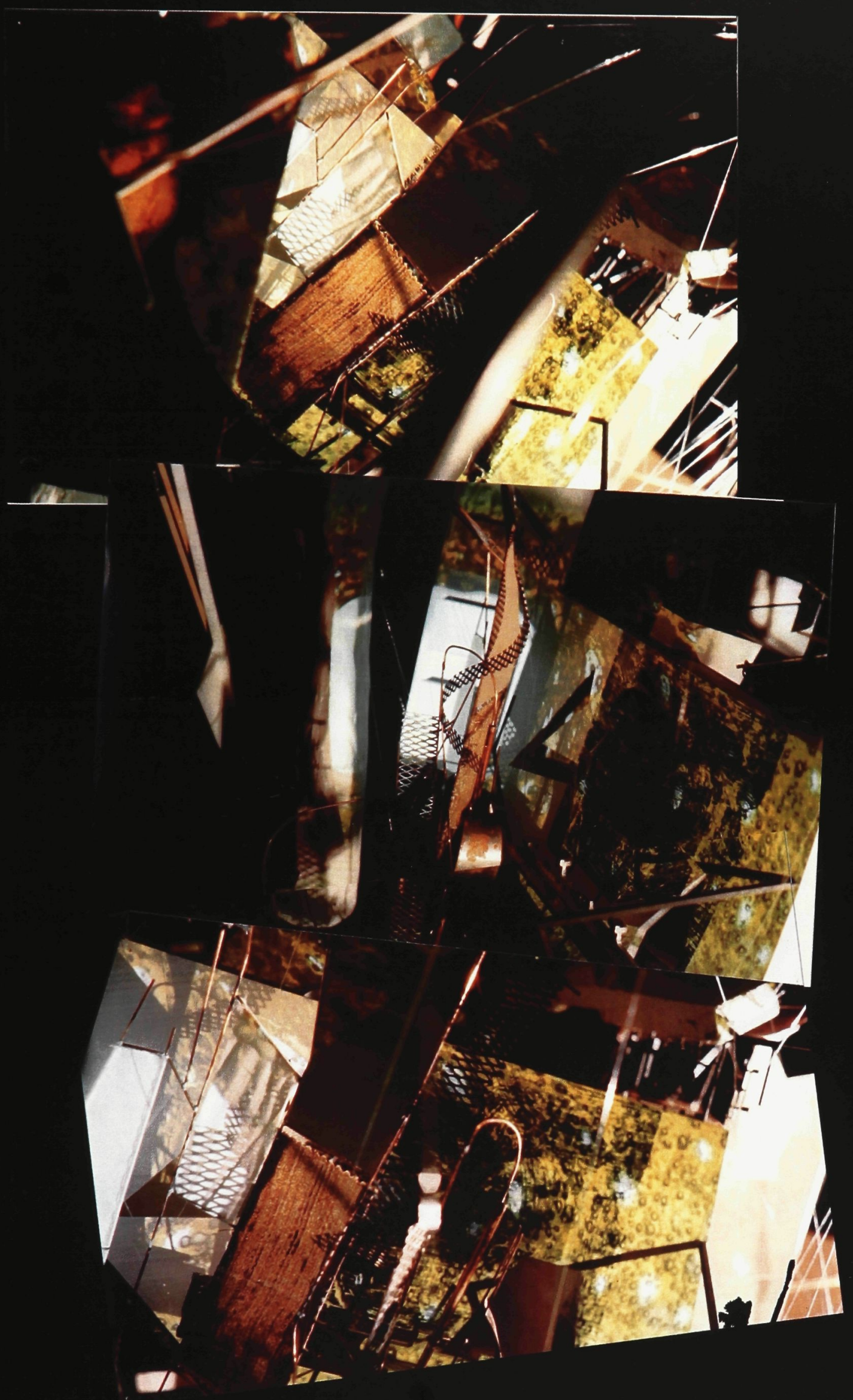

Plate 5

Step 2 


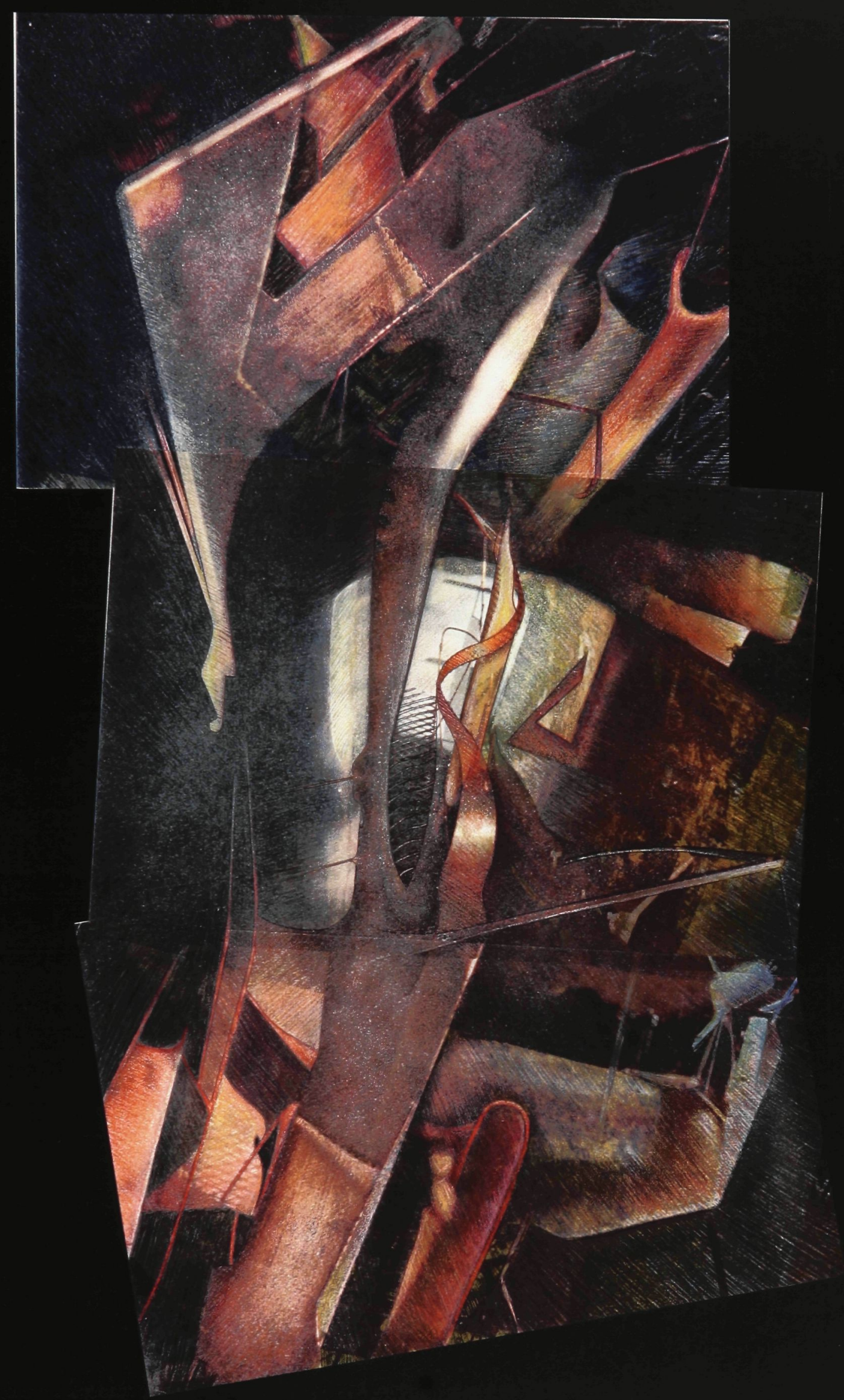

Plate 6

Step 3 


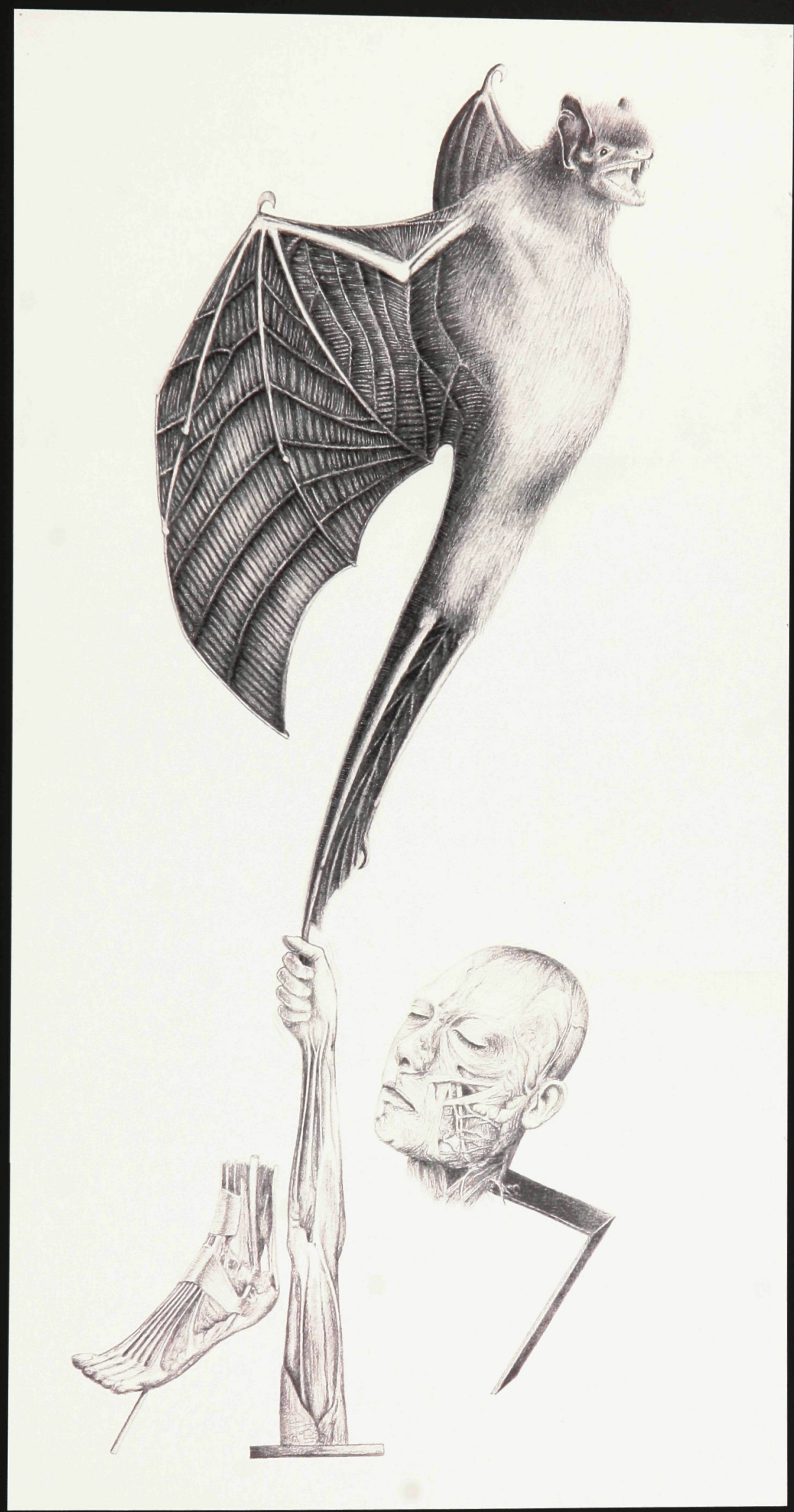

Plate 7

Step 4 
Sign as Narrative 

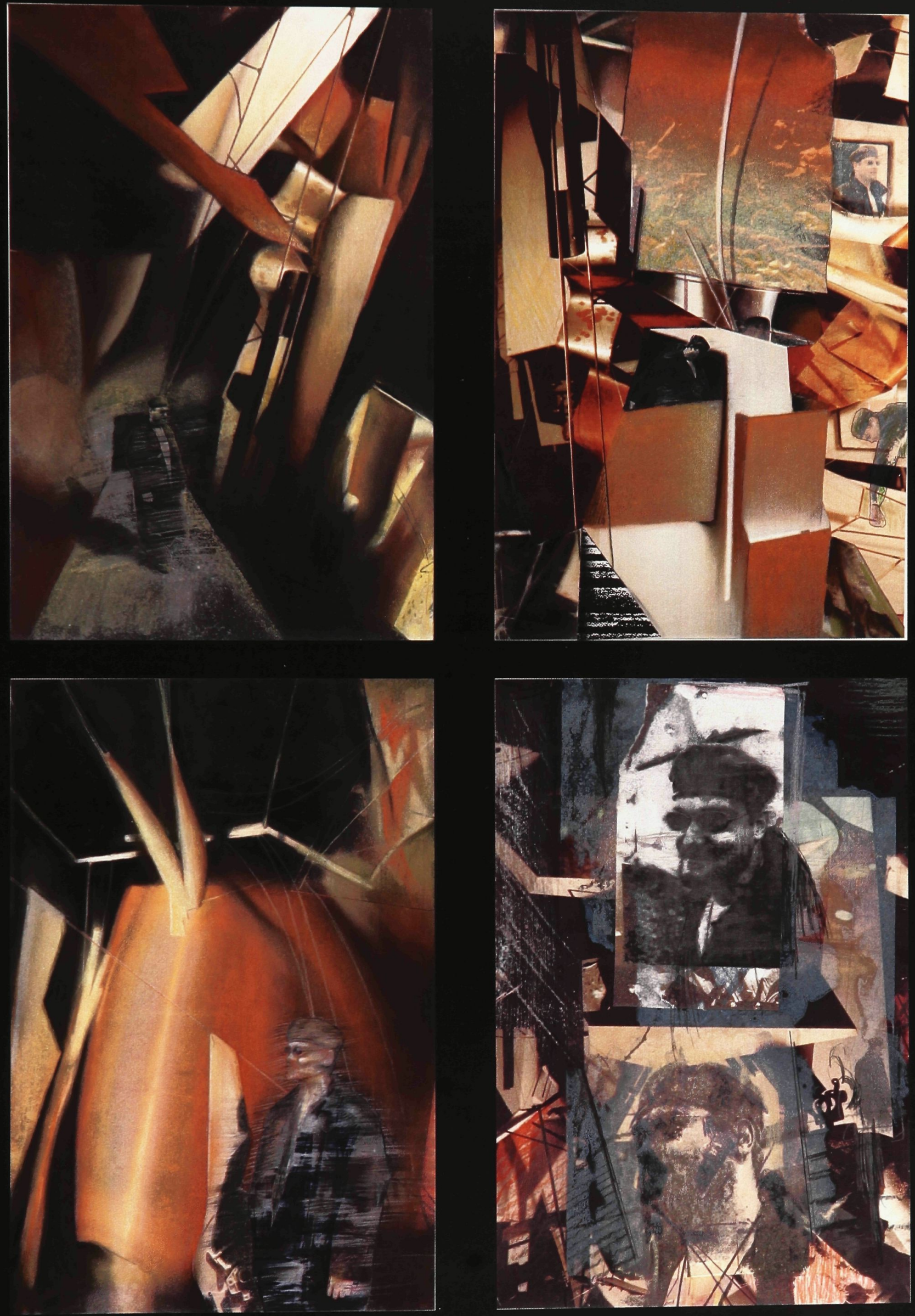

Plates 8, 9, 10, 11 

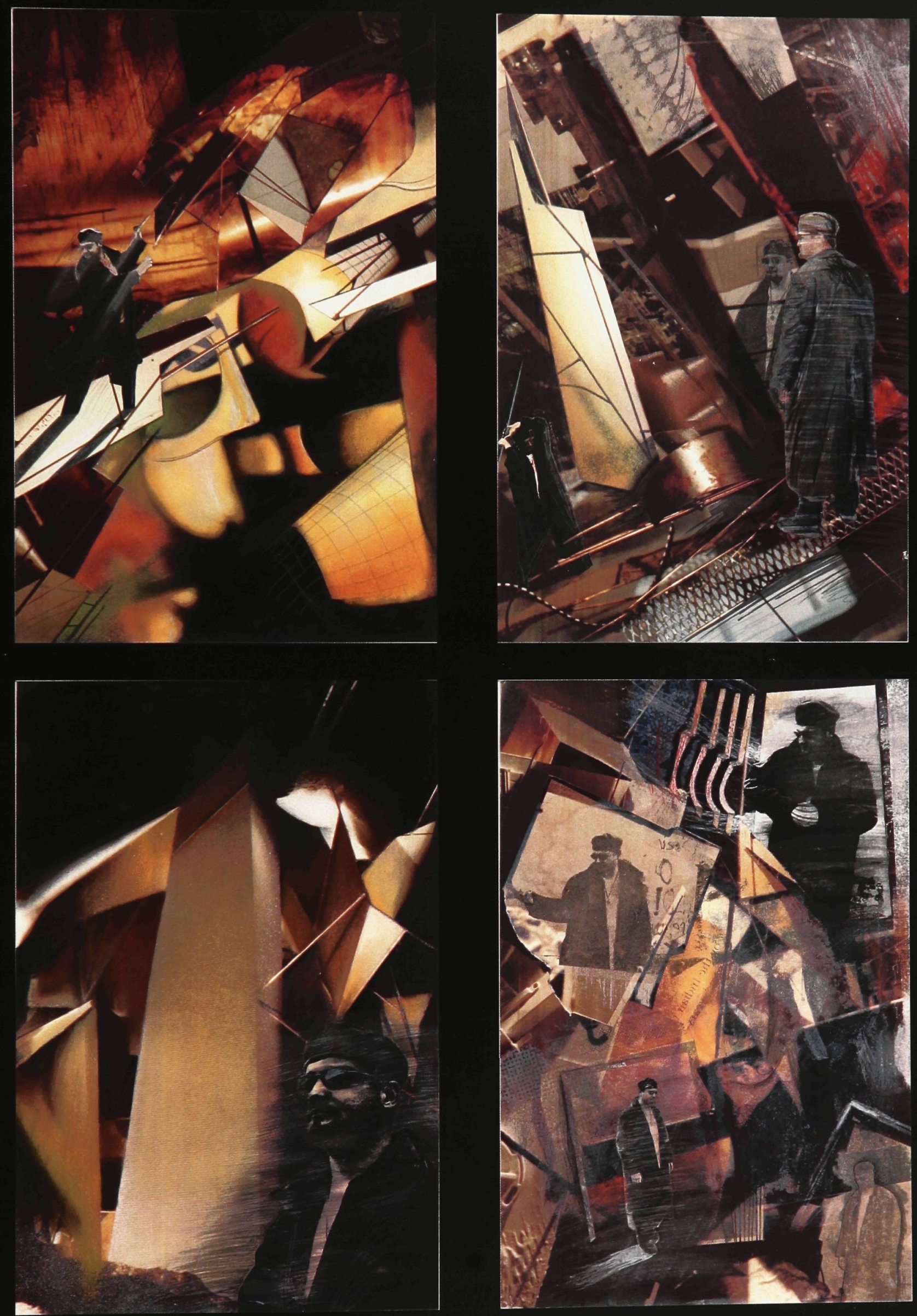

Plates $12,13,14,15$ 

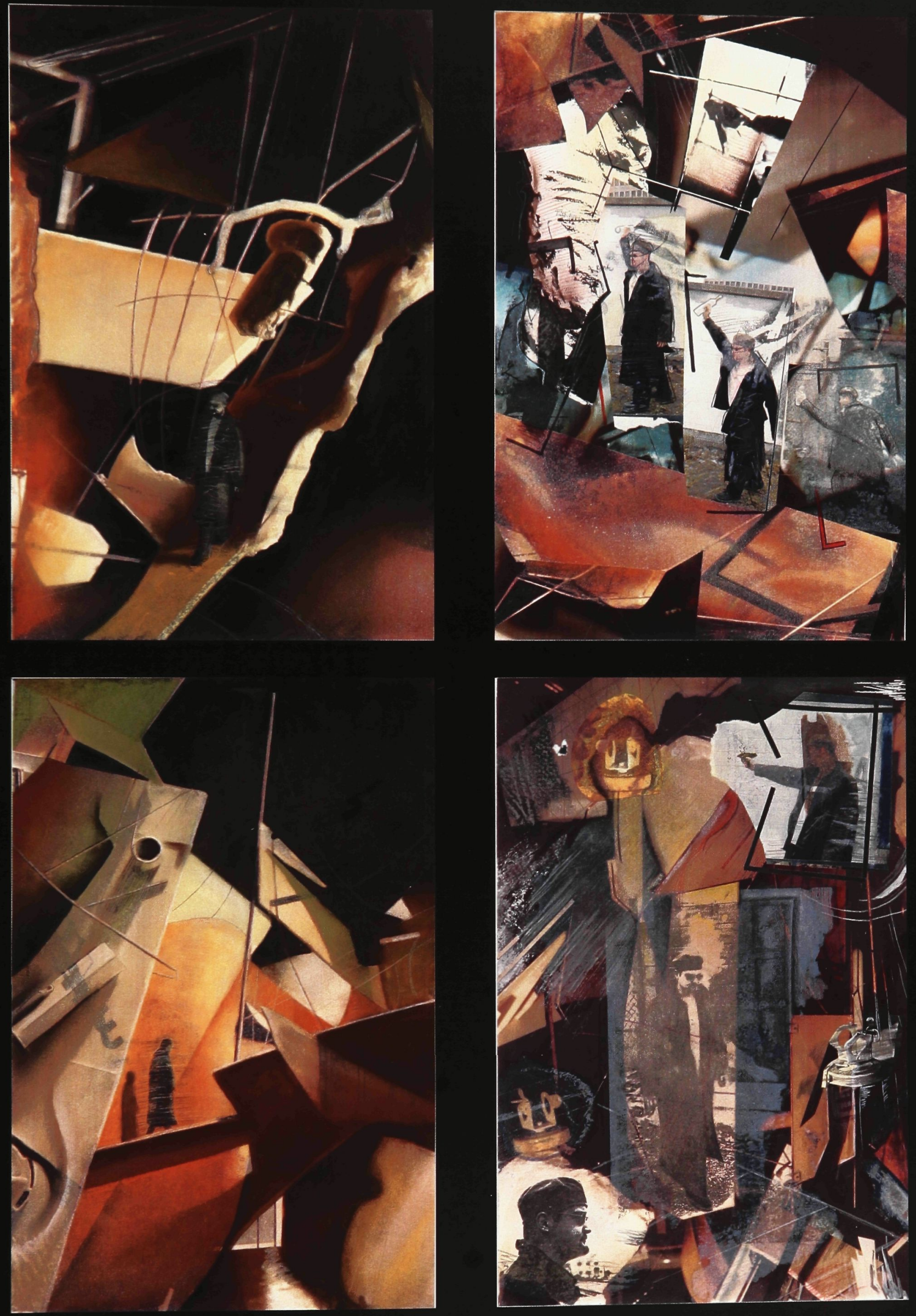

Plates 16, 17, 18, 19 

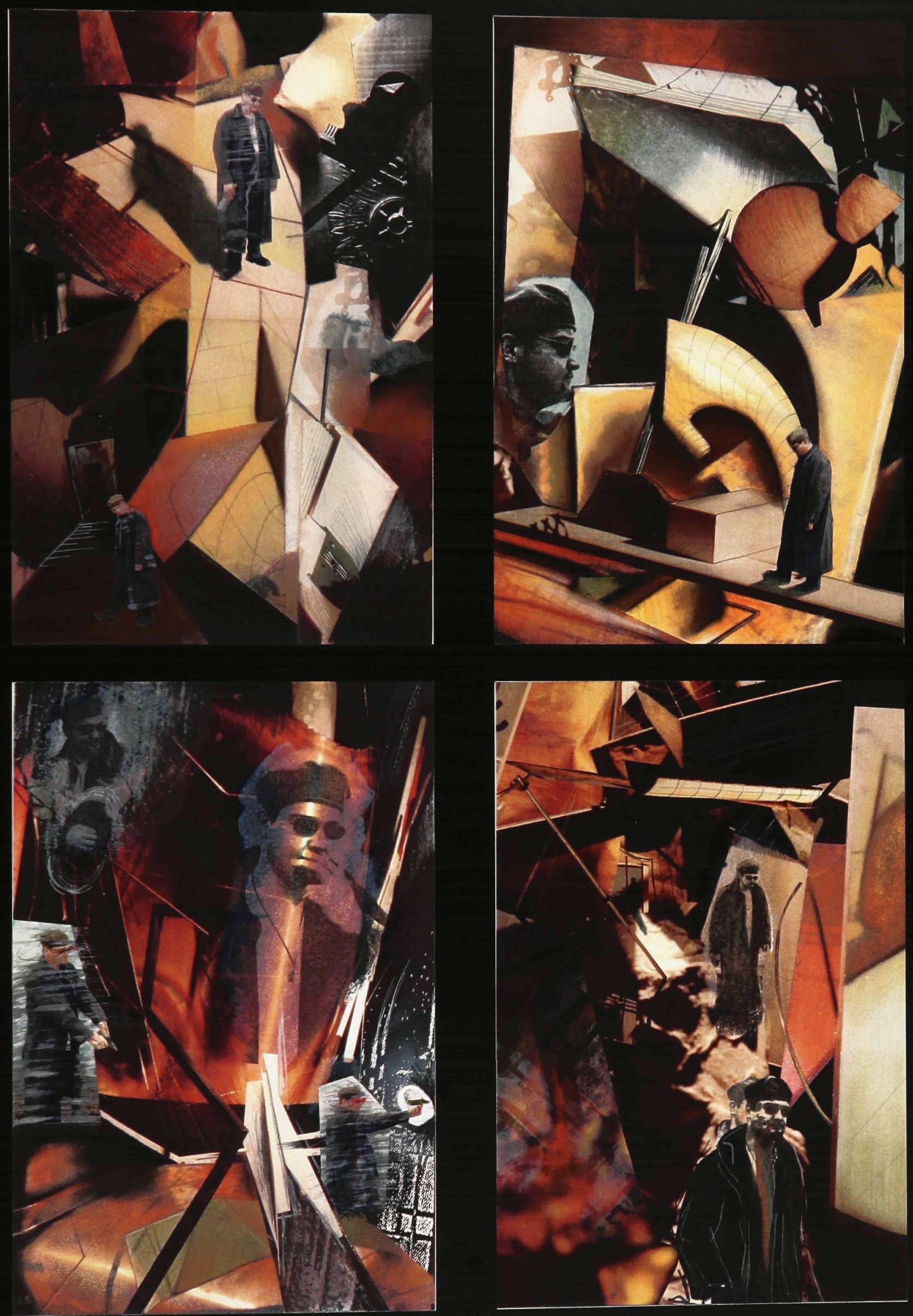

Plates 20, 21, 22, 23 

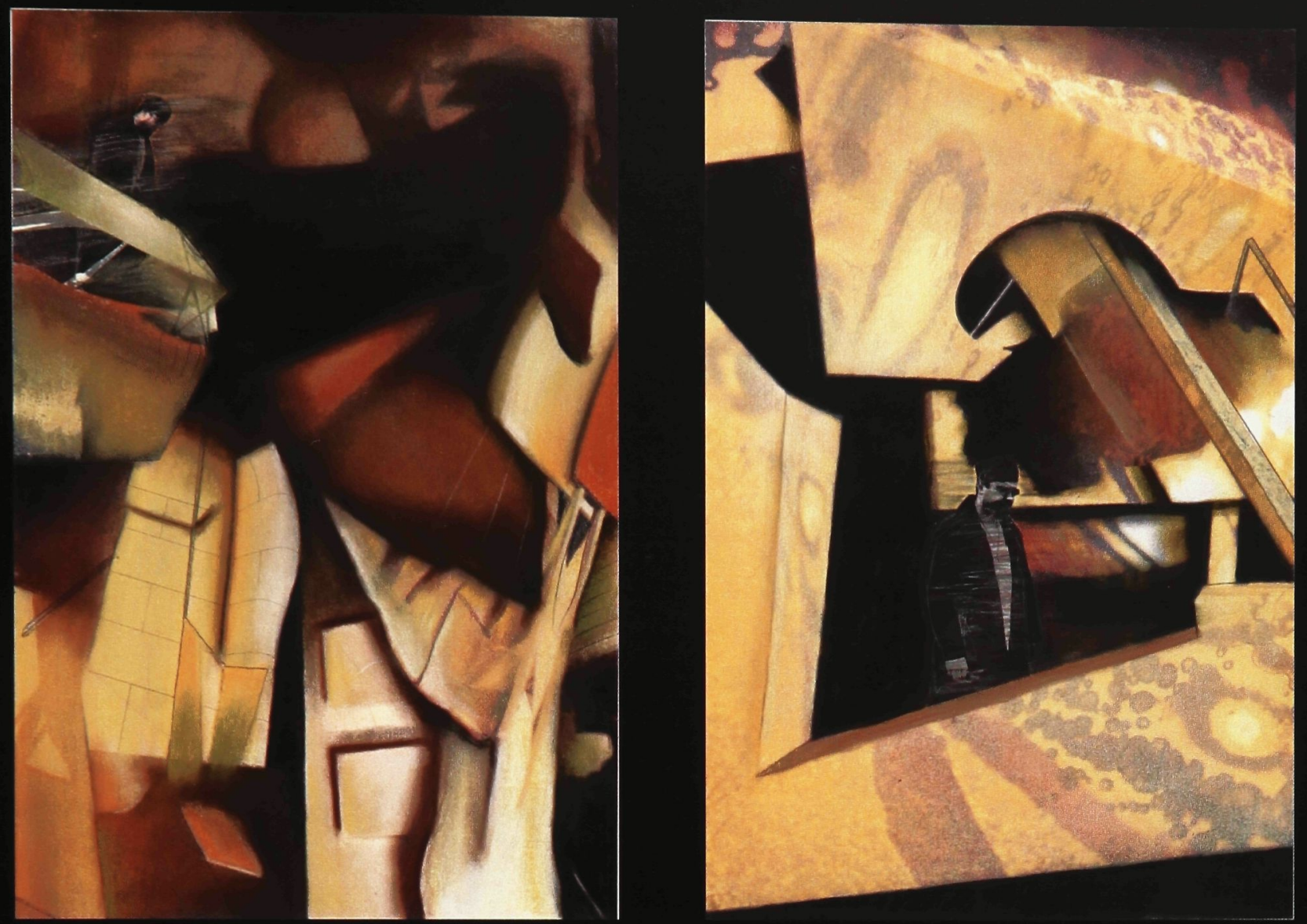

Plates 24 and 25 
Sign as Apostrophe (Video - refer to compact disc) 


\section{$\underline{\text { Audio Tracks }}$}

...And You Will Know Us By The Trail of Dead. "Baudelaire." Perf. Allen, Keely, and Reece. Source Tags and Codes. Interscope, 2002.

Bob Dylan. "Mr. Tambourine Man.” Bringing it All Back Home. Columbia, 1965.

David Bowie. "Station to Station," Station to Station. RCA, 1976.

David Bowie. "What in the World." Low. RCA, 1977.

Green Day. "Extraordinary Girl.” Perf. Armstrong, Dirnt, and Cool. American Idiot. Warner Bros., 2004.

Interpol. "Next Exit." Perf. Banks, Carlos D., Fogarino, and Kessler. Antics. Matador, 2004.

Pinback. "Sender." Perf. Smith IV and Crow. Summer in Abaddon. Touch \& Go, 2004.

Pinback. "This Red Book." Perf. Smith IV and Crow. Summer in Abaddon. Touch \& Go, 2004.

Pixies. "Gouge Away." Perf. Black, Santiago, Deal, and Lovering. Doolittle. Elektra, 1989.

Spoon. "Back to the Life." Perf. Daniel, Eno, Zarbo, and Lovejoy. Kill the Moonlight. Merge, 2002.

Spoon. "Paper Tiger.” Perf. Daniel, Eno, Zarbo, and Lovejoy. Kill the Moonlight. Merge, 2002.

Spoon. "Someone Something." Perf. Daniel, Eno, Zarbo, and Lovejoy. Kill the Moonlight. Merge, 2002.

Talking Heads. "Memories C'ant Wait.” Perf. Byrne, Frantz, Harrison, and Weymouth. Fear of Music. Sire-Wbr, 1984.

Talking Heads. "Artists Only." Perf. Byrne, Frantz, Harrison, and Weymouth. More Songs About Buildings and Food. Sire-Wbr, 1978.

Television. "Venus." Perf. Verlaine, Lloyd, Smith, Ficca, and Hell. Marquee Moon. Rhino-Altantic, 1977. 
Television. "Marquee Moon." Perf. Verlaine, Lloyd, Smith, Ficca, and Hell. Marquee Moon. Rhino-Altantic, 1977.

The Arcade Fire. "Neighborhood \#2 (Laika)." Perf. Win Butler, Will Butler, Chassagre, Parry, Kingsbury, and Gara. Funeral. Merge, 2004.

The Magnetic Fields. "I Looked All Over Town." Perf. Merritt, Gonson, Davol, and Woo. I. Nonesuch, 2004.

The Magnetic Fields. "In An Operetta." Perf. Merritt, Gonson, Davol, and Woo. I. Nonesuch, 2004.

The Secret Machines. "Sad and Lonely." Perf. Benjamin Curtis, Brandon Curtis, and Garza. Now Here is Nowhere. Reprise, 2004.

The Smiths. "Heaven Knows I'm Miserable Now." Perf. Marr and Morrissey. Hatful of Hollow. Rough Trade, 1984.

Tom Waits. “Bride of Raindogs (instrumental).” Rain Dogs. Island, 1985. 
Sign as Language 
Table of Contents: Sign as Language

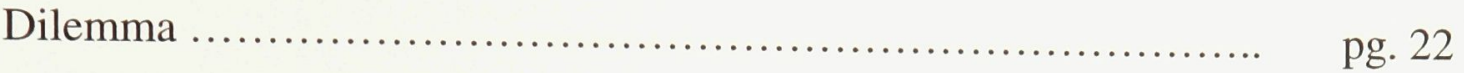

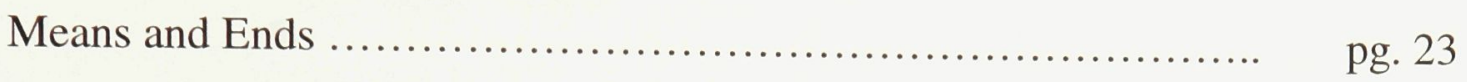

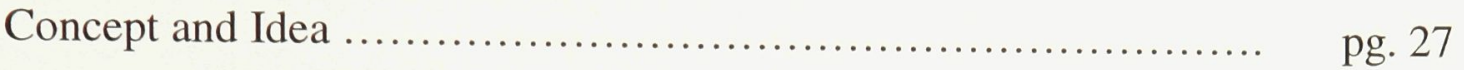

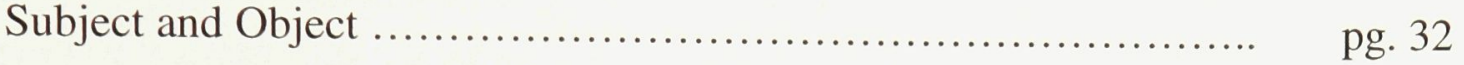

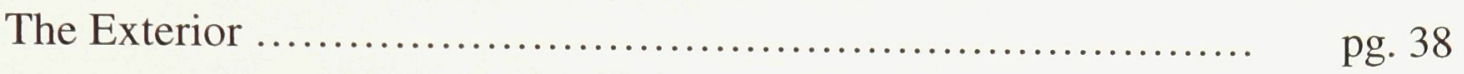

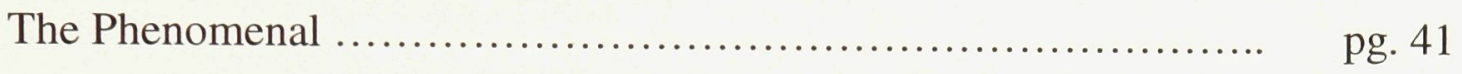

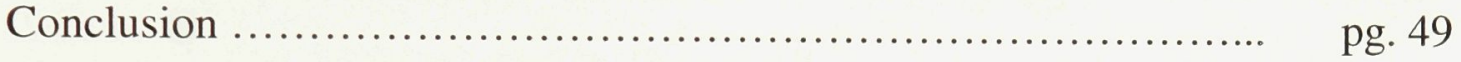

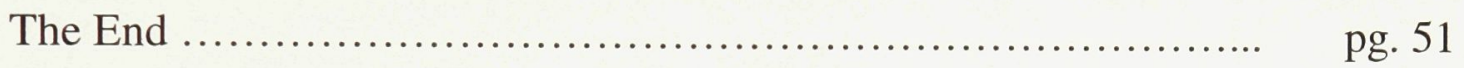

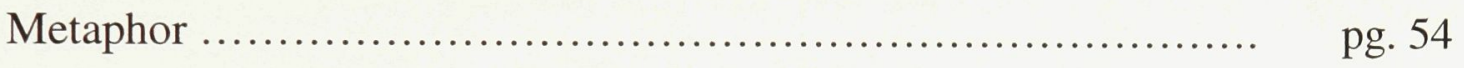

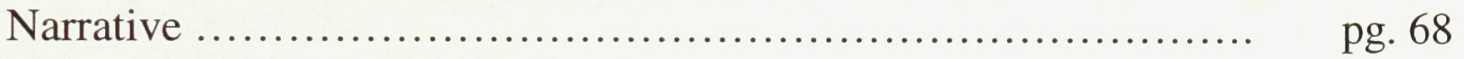

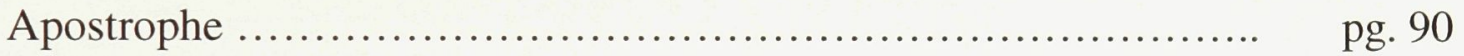

Language / Inter-subjective / The Beginning ................... pg. 98

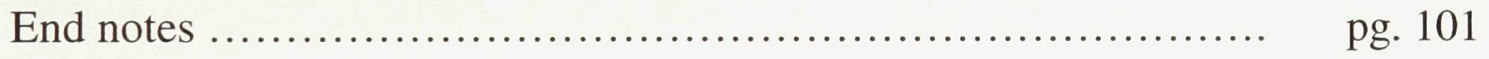

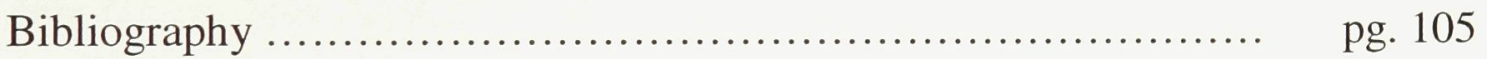




\section{$\underline{\text { Dilemma }}$}

'Architecture' has been in a state of crisis since the dawn of the modern era (late $18^{\text {th }}$ century to the present). Our ideologically-ridden discourse symbolize the collapse of an over-arching metaphor; thus we find ourselves marooned to the far beaches of pluralism, post-modernism, nihilism, etc. Humanity's well-developed technological consciousness is in tune with our status of impasse and has on its own accord developed its own will and course of action. This derivative self-will (technology) is in the decadence of its being. Technological 'values' have become officially human and its 'efficiency' has become a global religion, an empty and self-sustaining Being.

It is within efficiency that we currently find human activity and interest. We are truly 'within' this world-view when we regard it as a movement towards progress. This movement of the technological consciousness is that of an exteriorization of the self. It is only within the self that we can understand our actions in the world. Outside of our selves, the domain of 'self' is represented into the world as object and takes on a quantitative and virtual being. This quasi-being is the Being belonging to 'society' and civilization. A realm of shared disbeliefs and shared illusions. A time of oppressed subjectivity and authenticity. Humanity's worth is in accordance with the goals and values of society and peace becomes sustaining inaction.

This quasi-self is capable of being multi-selves. One can be a parent, a worker, a member, a taxpayer, a statistic, a chat room character, etc, 
simultaneously. Time and space have no bounds now. One can be on an airplane flying to Sydney and at the same moment be in the Louvre taking a digital tour. One can have a conversation about a certain celebrity's love life with a local boy in an Italian Restaurant in Kathmandu. One can see all the great art and architecture in the world without leaving one's own chair. One doesn't even need to form one's own opinion because it has already been formed by media and critics whose validity is their medium. All things deemed 'revolutional' appear on late night infomercials. We now are tourists at home and at heart. Everywhere everything is possible so long as it does not break any legal codes. This is the world of the exterior, the homogenous World-state.

Where does this leave our true self? Out of reach for even us? We must internalize our Being as Subject. We must search for meaning and Truth only from within our selves. Internally the will is projected out as action and as such is pure and 'complete'. To be critical of our world we must discover our own subjectivity and authentic being.

\section{$\underline{\text { Means and Ends }}$}

We live in a realm enframed by efficiency sustained by the exteriorized self, contained by 'civilized' Being. Architecturally and technologically speaking we can easily consider this notion of 'efficiency' as a system of 'means and ends'. "Whatever" means towards the most "efficient" end. As 
technological techniques 'improve' (accepted value) we arrive at the ends faster, and thus, more efficiently. This, in turn can be defined as progress.

The movement of means itself is that of and for 'progress'. In this way 'progress' as noun is the determined end or desired arrival and fulfillment of something. But the term itself signifies something that can never be truly fulfilled in its entirety. The 'progressing' or pursuit of progress is the yearn of progress as noun. It is in its essence unending as such. Within it 'time' is signified but it is itself atemporal. The act of 'progressing' signifies 'movement' (from a beginning, towards an end) which is human activity with an ends (desired arrival) in mind. Time is therefore all human activity acted in the 'progressing' towards the progressed. Time is the act and not the ends. 'Progressing' is therefore unending because the 'progressed' can never be actualized in Time. The 'end' is act-less, atemporal and un-human. Therefore the means is the end: the desire for endless desires.

Technology can never be efficient (as noun, as end), for if it could claim such a standing, it would have nothing to do with efficiency. The end is always a means or there would be no progress as such. When we enlarge this we already see the next obvious step in the global realm of technology. It is the realm of sustainability. When the condition of means and ends becomes aware of it-self and exists in what Hannah Arendt would classify as 'work', progress becomes aware of its inherent end. Progress exists in a quantitative world thus it contains quantities of 'stuff' that is finite and irreplaceable. Thus efficiency must transform accordingly but not in a manner that would reveal its own 
essence. The attention now turns to sustaining what is efficient by transforming the 'value' of what it is to be efficient, that currently being 'earth-friendly' or 'green'. Under this veil, the new ideals and values of sustainability have created new techniques, by-laws and aesthetics which are ever more on the same careless road of technology, drifting humanity even further into Exterior-Being.

Now let's leave the operational level and approach the speculative and theoretical level in terms of architectural process. What is to be investigated in this thesis is the relation of means and ends in the process of making architecture. The 'means' or 'architectural process' is that of designing towards a designed architectural object. In such a manner, the 'ends' would be the actual built entity. But in terms of a renovation, the end can also become a beginning, therefore means. Nevertheless, what is to note as the 'means' is what belongs to that of designing, and the 'ends' is what belongs to the designed, the architect's final 'act' (When the building is erected it no longer concerns the architect, except for prestige, publicity or legal responsibility). This designing (like progress) has no specific duration and as such is unending outside of a relation to an anticipated end. Its duration is what designing consists of and concerns: the process of becoming its determined end; the designed. The end is considered determined because without it, it would not require process to define it as an end. So, the role of the architect is the activity of designing in simultaneous relation to the designed, or in other words, the means is only truly means when it is aware and anticipatory of it ends. 
All designing is concerned and aware of its becoming 'designed', for if this was not the case it would have nothing to do with 'designing'. In the realm of architecture-means, there is a 'chronological processing entity' of designing which traditionally begins as concept or idea (to be defined later) and undergoes 'designing' until the desired design is represented in a set of working drawings (or whatever constitutes the architect's final act). As the design becomes closer to the designed, the process of designing becomes more ridgid and determined. Thus, the final design justifies the intial concept/idea. Or in another sense, the intial concept/idea is valid and necessary because it exists in and for the final design. Therefore the designing is 'allowed' to occur to bridge these two poles. The final design brings-forth or calls upon the intial concept/idea and in this way it too is determined because it 'functions' as means. But if the initial concept/idea comes to the architect within his subjectivity how can it have any character of a predeterministic end? It does because it 'concerns' itself with a predeterministic end. To be a concept/idea for designing it must be relative and thus possible for the designed. In this way the supposed subjective origin must have been corrupted in its essence. It could not have been born of the architect's subjectivity as such. It was a representation of a concept in the form of an idea that was 'considered' in the mind of the architect.

This process, as observed earlier in the document, is the movement into the 'exterior': a decentering away from selfhood. Therefore the 'means' itself is a process of exteriorization from the self as subject as it progresses towards its ends. The content and purpose of this thesis involves examining what exists 
before designing, before means. 'Something' that can be entitled at this time, 'pure-Concept/Idea': A pre-cognition that exists internally within the architect until the moment it is actualized and quantified as something for something. What quality or worth is this concept/idea when it is pre-destined to confront and become its end the exact moment it operates as such?

\section{Concept and Idea}

Saint Thomas Aquinas (1225-1274), an early philosopher/theologian concerned with epistemology, began to differentiate between what is Concept and what is Idea. He states that individual man or 'specific being' is an imperfect being. The imperfection which one possesses is in comparison to the virtue of its proper species. ${ }^{1}$ The specific being of one individual differs from another individual (what one is). In every being there is imperfection in proportion to the perfection it might have, to which an other(s) has. ${ }^{2}$ The individual is not absolutely perfect in itself but it is part of the whole of universal perfection, which is the collective species taken together.

There is a remedy for this imperfection and it is found within another individual. "The perfection proper to one thing is found in another." 3 This is how knowledge is acquired for Aquinas. It is possible because once something is known by a knowing subject, it is contained and preserved in the subject as now part of its being (aliquo modo). In this manner, the perfection of the whole universe can exist in one thing (subject). ${ }^{4}$ 
The perfection of one thing can be another, but not as it did within the other who primarily possessed it. "The determination of the forms and perfections of things is due to the matter that limits them."5 Therefore, something can be knowable only when it is separated from matter, when it is immaterial. Thus, the immaterial of the thing knowable demands the immaterial of the knowing subject. "The mode of immateriality is the mode of knowledge."6

For Aquinas, the concept (or intention) is that which is conceived within the knower concerning the thing known. The concept (for Aquinas) is neither the thing itself nor the substance of the intellect but rather a representation (a likeness) of the thing understood. This concept or 'verbum' is, therefore, that by which our intellect understands a thing other than itself; it arises from one thing and represents another. "It is a 'propago', an emanation of the intellect, but it is not part of its essence."7 The thing understood is not the thing of knowledge. It is immaterial; it is outside the knower. Thus, the thing cannot be understood qua understood because it would need to be in the knower as it is in material reality. The principle of knowledge is therefore only a likeness of a thing known. "The concept is not the object of the intellect, it is the medium by which the thing is signified: It signifies. It is a sign which may be defined as that which leads to a knowledge of another." 9 A sign is any known thing in which something is known.

The idea is a form, which something imitates from the intention of an agent that determines its own end. Something can imitate a form in two ways; 
from the agent itself by determining its own end, or accidentally (or chance). A form is; the likeness of the thing understood in the knowing subject, the understanding insomuch as it is understanding, as the thing understood by which the agent makes something. ${ }^{10}$ "Distinguishing between the concept and the idea on the basis of the distinction between practical and speculative knowledge. For the end of the speculative is absolute truth, but the end of the practical is operation."11 The practical intellect (idea) causes things and is the measure of things, which are made through it. The speculative intellect (concept) receives from things thus things measure it.

The idea therefore is the concept having assumed the role of object of the intellect that can be 'considered' and produced as the real. It is a mental sign or representation of a thing considered. The mind can only contemplate what is internal or part of its being, therefore, an 'idea' is nothing other than that which is the immediate object or the closest to the mind when it perceives an object. Thus, the architect 'conceives' idea, and it is only idea that can be sought out into representation and to be processed into design. Is realm of idea the realm of the architect? Where and how does the Architect call upon Concept? How can one conceptualize if a concept is received from something else?

If we truly believe in Aquinas (or Kant for that matter), the concept is a relation. It is a relation between Time and the eternal. Therefore the Concept (the concept of all concepts or Absolute) is something that can never be experienced because it is in relation to Time and not Time itself. The experience of the Concept is thus transcendental, outside or precedes Time. “... 
they 'precede' everything that is in Time, they are 'before' Time, hence they are valid at every moment of Time, and, since they exclude Time, they cannot be modified, they are a priori." 12 It is "intuition" that presents a manifold content (which allows man to think) that is given to man and not produced within man. ${ }^{13}$ Man can use his eternal Concepts provided that he can 'schematize' them in relation to Time. ${ }^{14}$

In this system man is not free. His free will, the 'Transcendental I', operates in spatial-atemporal relation to Time before Time. ${ }^{15}$ The Concept therefore could not exist for man. To understand the Concept we must look at Hegel (as interpreted by Alexandre Kojève, 1902-1968).

For Hegel (according to Kojève), The Concept is or equal to Time is or equal to Man. Man endures and defines Time so therefore Man is Time.

Human time is Time. The Concept for Hegel can be defined by;

"To be sure, the Real endures in Time as real. But by the fact of enduring in Time, it is its own remembrance: at each instant it realizes its Essence or Meaning, and this is to say that it realizes in the Present what is left of it after its annihilation in the Past; and this something that is left and that it re-realizes is its concept. At the moment when the present Real sinks into the Past, its Meaning (Essence) detaches itself from its reality (Existence); and it is here that appears the possibility of retaining this Meaning outside of the reality by causing it to pass into the Word. And this Word reveals the Meaning of the Real which realizes in the Present its own Past - that is, this same Past that is "eternally' preserved in the Word-Concept."16

In short, "Being revealed to itself by an empirically existing Discourse." 17 "Whatever is subsumed under the concept is a 'moment' of the whole Concept and, as a moment, expresses the whole Concept and is valid only as inseparably 
united with the Concept, deriving its determinates from its identification with the whole." ${ }^{18}$ Hegel's Concept is that of concreteness and not a form of subjective or 'abstract' thinking. (The way an individual represents to itself the universality of the object in thinking) The Concept is something that cannot be grasped by the senses, it is not for man but is Man. Subjective thinking towards an object is only a reflection external of the object in reality. "To come to grips with its universalized object, it [thought] must also think the particularities of the object, which it can do only if it thinks the particularities of its own structure."19 Only within the unity of subject and object can Truth or Concept be revealed.

"In one sense the concept of which we are speaking is still merely a 'form' of subjective thinking: and yet it has no other content than itself - it does not 'receive' a content from outside itself; it is not simply a form imposed on an alien content. It is, nevertheless, the form whereby whatever its content is is determined to concreteness. What this implies is that the subject which gives determinateness to its own content is the very source of concreteness and, therefore, is itself preeminently concrete, and this, in Hegel's thinking, is to say that the subject is spirit, wherein the initial total abstractness of mere 'being' is progressively concretized. Thus, the concept, even though a subjective activity and, hence, distinguished from its own objectivity, is, nevertheless, the source of its own objectivity, since it does what the so called 'concrete' out-there cannot do, that is, unify the diversified manifold of the 'given'. There are, it is true, determinate abstract concepts, like 'man,' 'house,' and 'animal,' but because they are only universal [character of sameness with itself that the concept retains in each of its instantiations] - neither particularized [the generalized instantiations, in which the self-sameness of the universal remains undisturbed] nor singularized [the ultimate instantiation, wherein are reflected both the determinacy of the particular and the self-sameness of the universal] - they are undeveloped and do not have the concreteness of the authentic concept. The determinateness of the concrete concept is 
precisely the negation of the indeterminateness of the abstract. ${ }^{, 20}[\text { bracketed }]^{21}$

This almost existential reading of Hegel sheds new light on what Concept is in relation to Being: self-determined meaning within the unity of subject and object. But what then is truly objective about the object? If what is determined as 'object' is simply a subjective interpretation or 'idea' in the form of the universal, then does in not belong more authentically to the subject in thought as the object does outside of thought?

\section{$\underline{\text { Subject and Object }}$}

If we consider 'objective' as something concrete, or something that exists outside the realm of interpretation, then we are to believe that all beings thinking, viewing, inhabiting, understanding, etc, some object are constructing the same mental 'object' on 'its' own terms. But is this possible? If it were true or untrue how would we know? If all objects enter our thought through a subjective 'immaterial' construction called 'idea' by way of concept (partial, subjective in its reckoning) and as 'I' can only exist as 'I' (this human and no one else) then how could such sameness in another happen as exact? For example, if we consider a table, we are already picturing in our minds a different table. But we could all draw the table we were picturing I bet they will all share the same tableness character that distinguishes itself from a bed for example. So could it be said that even though the table pictured is a subjective 'idea' of the concept 'table' and thereby different, the concept itself is universal 
and thereby objective? Or does the entitlement through our language, which thought contains and exists, put limits on something that is itself limited. Is the word 'table' in empirical existence with the concept 'table'? If when we, in language, say 'table', we think in language to have an 'idea' of table. Is the concept of table only in language?

In terms of our use, an object is that which sits apart from us to be used to enter into our thought via the concept in order to be contemplated as such. However, the moment the object reveals its presencing to us and enters into thought it ceases to become object and becomes subject, a subject of our contemplation. At this moment it ceases to become subject and becomes idea. Within the idea the original object is represented to us by our interpretation of such thoughts that considered the object originally, via concept. Object becomes subject to thought, becomes idea, object of thought and therefore original object as immaterial or representation becomes part of our being, as Aquinas has noted. Within us we give it form and content. Object and subject are synthesized at this moment of contemplation.

What occurs to us, the contemplator, when this occurs? One must always remain in contrast to the object/subject of contemplation. Within the event of the occurrence, the subject cannot contemplate the subject. If it did the latter subject would be the object under contemplation. So when we first encounter an object to be contemplated we must enter only as subject. But when the object becomes the subject of contemplation, we correspondingly become object, respectively. It is in this exchange that we must note the action of 
inversion. When we, as subject, respond to an object, it calls upon us to contemplate it-self. What is this unknown force? Is it the Concept? Is it Kant's 'intuition'? Is it even a force?

If the force is and always was from within the self-contemplating, the action must be a reaction deployed by recollection. Let's suggest that this 'force' is not a force as such but rather a beckoning-within. There, the 'concept' as such is active only insofar as it becomes a sign. This sign however does not emit any Conceptness but remains empty until called upon by the one who is to contemplate said object. Therefore if no force is entered into the self by means of concept (or such) the force that occurs is a beckoning-within, which happens solely within the self by the self. It is rather an offset than a true motion towards something. What appears to occur is a momentary loss of selfhood into recollection (into the sensible past). This 'loss of self' (in the apparent realm as subject) is a split subjectivity whereas the self takes on dual characteristics of both subject and object existing interchangeably. If recollection belongs to the realm of sensible past then it is only from within ourselves that we can posit ideas to the mind, or in short, to understand.

Consider again, the table. Before the table enters as a subject of contemplation we ourselves anticipate (act in and for ourself) and at once become a splintered self consisting of both subject and object. We therefore momentarily lose our subjectivity (in the sense of total, complete and passive) and enter into what is and what has been (sensible past), a quantative realm of past 'ideas' (the 'object' half of self), which is held as such by 'our' concept of 
self, 'our' revealed Being of being (Active subjective). It is here that the object of contemplation (table) enters as subject, and is given form and content through recollection by a conceptual 'self logic' tie (semblance or resemblance), then enters thought as idea, immaterial, or representation of said table. We understand and respond to phenomena only through what has been pastphenomenona. The existing ideas held within Concept are acted to resemble the phenomena of contemplation to the conscious in such a manner as metaphor is used in language. The metaphoric subjective is the genealogical 'logic' (of the sensible past) that constitutes the Concept. We can only know through what is known. This act of perception (as such) is never so vivid as when we contemplate something 'mystic' or new. There is a constant 'scramble' of thoughts trying to 'make' sense of what is in front of us. We can only 'make' or represent something of knowing by semblance through what is known. This semblance occurs through the phenomenal space by Concept towards Idea.

This 'motion' of recollection is synonymous with Hegel's notion of Concept/Time as considered earlier in this document. “... [it] realizes in the Present what is left of it after its annihilation in the Past; and this something that is left and that it re-realizes is its concept." 22 This motion of "annihilation" into the sensible past to be passed into present is the 'act' of the Concept. What is present to the mind after this 'act' is Idea. Thus the present (the contemplated/contemplating) is made-manifest after the subject of contemplation (future) is acted into the sensible past to be "re-realized" by 
semblance (the Subjective) and posited (via Concept) to the conscious mind as present (as Idea).

The Concept is what constitutes Subjectivity, thus it is and/or equal to the Subjective. The Concept 'creates' Idea(s) from semblance within the Subjective (made up of all and absolute 'Idea'). When the Subjective (selfhood) becomes split into subject/object, an 'idea' is constructed (or made apparent) to the consciousness. The 'idea' of said table is then the table under contemplation and exists empirically within the contemplator. When it exists apparent to the conscious mind as 'idea' it is outside the Concept/Subjective. In other words, the Concept is 'means' towards Idea which is 'ends'.

What has been determined is that the 'process' is the movement from means to ends. This process is therefore the first act of departure from the self (Subjective/Concept), into the Exterior-self. If the means is the Concept, its essence belongs to ends or Idea. But if Concept 'belongs' to idea it would be impossible to enter, experience, endure and reveal the Subjective. All 'process' would be externalized, and the 'Concept' would not be Concept but rather an over-arching Idea as manifold. Man would therefore be at his essence externalized if Concept 'belongs' to Idea. Therefore idea must and only 'belong' to Concept. In this manner, Concept is the root for idea: it creates form and content, and allows things to take appearance from out of itself. Therefore the Concept is not the 'means'. For it to be true and forever valid as self it must be 'ends' and accordingly, Idea would be the 'means'. This system gives opportunity for the self to reveal the self to the self. This pure and spontaneous 
act that exists before thought would embody absolute Will and

Concept/Subjective. When consciousness becomes aware that it was an 'act', Idea will be formed as the external-self response (self-reflection via thought/language), and will appropriate 'means' for the 'act'. Therefore Idea as means rationalizes post-Concept/Subjective to the consciousness which insomuch is understood as 'end' (autonomous act). The 'act' is thus internalized as event (pre-thought, Subjective) and also internalized in thought via 'introspection' (rationalizing the act as from and by the self). Subjectivity can then reveal (endure) and contemplate the Subject/Object split in the conscious mind. The self is therefore Absolute Truth and Knowledge.

The use of this system (ends to means) is possible for architecture only when one conceives architecture not as the built, but rather that which concerns the architect - designing. Therefore the 'ends' being the designed would 'process' towards the 'means', the designing. The designed would be a freewillful act of the architect as active Concept/Subjective sans Idea as mademanifest. The latter 'means' would be the recollection of this act. This would be considered post-rationalizing by introspection and not post-justifying. The action of the act is 'justified' by its being total and complete (Born within). The context for the 'post-rational' would be to endure consciously in the Subjective as Idea for a meta-understanding of the self. In other words, to see the self from outside but to remain as self: to be conscious of being both Subject/Object simultaneously. 


\section{The Exterior}

The exterior is the realm of the Objective, therefore it is for the self as equal as it is for another self. An idea is within the self but it is for something else, therefore it consists of something else.

It is the Subjective that deems something objective, e.g. the table. The tableness that belongs to the self as what signifies something as table is the semblance of 'idea' table via the Concept, 'the essence of tableness'. The Subjective determines 'idea' table and correspondingly conceives the 'actual' table (of/in contemplation) as a sign of 'tableness'. This sign is created from the Subjective and as such becomes objective. What is to be noted is that the 'objective' as such never leaves the Subjective. It is held objectively by the Subjective. The Objective as something other than Subjective is an illusion. It is a by-product of the Subjective as Idea. The Objective is Idea. Within this 'illusion' of Objectivity (as other), the sign is considered as real (separate from us) as the object under contemplation. As object, it is assumed that all other selves will come to the same tableness conclusion while contemplating the same table. The idea/object table as universal sign is exteriorized from the Subjective if the sign is deemed Universal.

When Absoluteness is permitted to be in objects and not inclusively in/as the Subjective/Concept we arrive at a concrete and universal 'objective-truth'. We encounter the 'Other', a force from outside the self. As Aquinas suggests, we remain as subjects for this Other who permits us revealed Truth. In this 
way, the table is 'allowed' (illusion oppressed) to exist as object table because we are singular human being and not Being as omnipresence. Objects exist because Beings exist. This is the first exteriorizing condition of the self.

Within the realm of the Objective comes the realm of Exterior Truth(s). These are everything and all considered 'Universal'; philosophy, theology, politics, science, mathematics, society, history, etc, all that claim truths external from the self (your-self). All of these 'systems' are accepted (or not, but still exist as) truths that comprise our world and continue to shape our very Being.

The Objective embodies/creates the 'institution of architecture' as something universally recognizable and constitutes the Real as a World of signs accessible to thought and language, etc. Here quantities and qualities are established as truths and architects are ones who act within. This is the Exterior. Within this realm the architect is free to act but his acts are not free. The Subjective/Concept is enabled and denied by Universals sustained in a World of 'Ideas' and concrete Truths.

Therefore, a truly 'meaningful act' (free act) of architecture is one directly conceived within/from the Subjective/Concept. For this, as above, the architect must not design for any end, the end must be the revealed self, the act of the 'designed' (the entirety). There can be no 'means' (idea, the exterior); there can only be 'ends'. If 'means' is taken into consideration, the 'ends' is corrupted rendering it determinate and not able or possible to enter the Subjective. This then, correspondingly, corrupts the 'Other' also as the 'means' takes on an objective function creating a Universal or Exterior truth (this way of becoming 
and no other) which blocks the 'other's' Subjective and exists void of Truth and meaning. The designed's becoming, intention or meaning is the becoming, intention or meaning of the self respectively.

When the 'ends', designed (architecturally, sans process, etc.) enters reality as object (through its transformation by Subjective) it is represented externally as sign for the sake of the Other. This representation of the Subjective is the existence or fact of 'our' act in the physical Real. The Subjective now externally posited into the World rests as Idea (for the self to reflect and for the 'Other' to internalize). It is inevitable since the 'Other' is not 'our-self' (singular being) and cannot enter 'our' subjectivity. Thus the Other is required to 'make sense' of 'our' act through the representations set forth by making/speaking/etc. It is only within another's 'making sense' or semblance of Idea via Concept that 'means' (as Objective) is suggested. Reasoning is in place to suggest what, why, when, where, and how the thing (the designed) was to take 'this' form and content. Like the table, the two participants (architect and client for example) contemplating a designed piece of architecture see the designed object/sign in/for their own terms. The sign remains for others to see, interpret and discuss.

It is through the reasoning of the 'Other' that 'means' first appears in this system. This occurs when another 'makes sense' (interprets) some-thing/sign. The 'Other' then, correspondingly applies form and content (in the manner of Concept/Idea as explained earlier in the preceding pages) to what has just been contemplated to be known/internalized. The 'exchange' that has occurred 
between one and the 'Other' is the response of the 'phenomenal', 'the space of inversion'.

The Phenomenal

'The space of inversion' is the splitting of the self into both subject and object interchangeably when one is contemplating something that is other (sign). This 'permits' one to act within the Subjective and posits into consciousness/perception the 'Idea' as/for what one is contemplating. While the act of contemplation occurs, the object under contemplation inversely mirrors this action of the contemplator (subject/object), as perception is made-manifest. The contemplated object is 'sign' before the act of perception is acted. The object/sign becomes subject under contemplation and subsequently returns to object again as 'idea' after contemplation. The action is therefore reciprocal between both parties involved (contemplator/contemplatee). This 'space of inversion' is the phenomenal exchange between the parties within empiricism. It is acted through the senses by the Concept/Subjective and posited into the sensible-conscious present as Idea.

The 'to make sense of' act is the experiential fact of the phenomenal. As mentioned above, this can only occur when the originator (architect, artist, etc.) has created the 'ends' by no 'means'. What this suggests of course is that all inherent 'meaning/truth' is for/from the Subjective and should remain for/from the Subjective in all participants included for a pure phenomenal exchange. It 
does not permit any Objectivity to occur since any 'Universal truth' is void of any concreteness (because there were no 'means'). Thus the Other of the exchange is free to interpret and posits their own 'means' as 'Idea' directed by their Subjective.

This phenomenal exchange can be illustrated in the work of British painter Francis Bacon. Bacon (1909-1992) was considered by some critics to be a surrealist but his paintings were never created with a surreal mentality as such. He was not interested in the sub-conscious, autonomous, or dream states for his inspiration, but rather focused his interests on the 'levels of sensation' and the 'act of perception'. Bacon's subject is the sensational with the aim to affect the potential viewer directly and deeply within their nervous system as an immediate response. "What is a painted on the canvas is the body, not insofar as it is represented as an object, but insofar as it is experienced as sustaining this sensation.” ${ }^{23}$ See Triptych May-June (1973). [pg. 45]

The "sustaining" of the sensational occurs by the passing of one sensation 'level' or 'area' to another. ${ }^{24}$ It effects all sense organs at the primary root where they are acted together in unison. Bacon is therefore not painting for a (single) response or effect but rather a multitude of sense 'occurrences'. This is the prolonged phenomenal act (to make sense of act) as sign 'passes' through the conscious present into the sensible past (Subjective/Concept). The enduring of sense 'occurrences' is the 'action' of the Subjective/Concept presenting 'Idea' to the conscious mind through semblance with the sensible past. The ‘sign's' proximity to one's sensible past (something of great resemblance from 
what has been sensed) dictates the amount of 'levels' or endurement experienced by the subject contemplating. When the 'sign' is implicitly recognizable (Objective/Means) the endurement or 'passing' is minimized. When the 'sign' is new or foreign to the sensible past (Subjective/Ends) the endurement is maximized. The 'time' of endurement is suggestive by the individual's Subjective power-influence over the conscious and not from the 'sign' itself, as something outside the individual. The less the 'sign' suggests 'means' (inherent by original authorship or by the individuals sensible past these are equal and the same) the greater the initial-original-act (Concept) from the sign's creator. In other words, the creator has created an 'end' without 'means', an autonomous, empty 'sign'.

Bacon, having succeeded in this phenomenal exchange has thus painted the 'ends', and as such, penetrated the viewer within their Subjectivity by way of 'sign'. This exchange, the space of inversion, exists as a dialectic between the painted (sign) and the individual viewing. The inversion occurs as a 'communication' between, albeit, the 'force' is only from within the subject (individual) and no force is from the sign it-self. The sign is an empty-signifier until 'Idea' is formed of the pre-perceived 'empty sign'. The 'space' of the inversion (as subject turns internal - objectified self) is illustrated as the endurement of the sensible (as Concept brings-forth Idea of). The 'ends' endures Subjectivity/Concept. The individual is free 'to make sense of' independent of an Other or Exterior 'force' ('meaning' given, truth 
presupposed) and thus the individual is free to give his own accordance/meaning/Truth to the sign.

Jean-François Lyotard describes this phenomenal exchange or 'passing' of sense levels as a state of "passibility";

"If we are in a state of passibility, it's that something is happening to us, and when this passibility has a fundamental status, the donation [what we are presented with as we stand before it] itself is something fundamental, originary. What happens to us is not at all something programmed, grasped by a concept. Or else, if what we are passible to has first been plotted Conceptually, how can it seize us? How can it test us if we already know, or if we can know - of what, with what, for what, it is done?"25 [brakets mine]

Bacon combats this 'Idea/means' reading by subverting the 'content' of perception by the 'structure' of perception creating an "illusion of Idea/means" by creating 'ends' only. This is accomplished by the figuration of subject of his paintings to act as a 'locus'. The locus is the space of the event as the event itself, or in other words it is the 'ends' insomuch as it is represented for the viewer as 'ends'. Therefore as 'the event of the event itself' it is not concerned with the representation of a perceived sequence of events (a.k.a. narrative) but rather the representation of 'perceiving' as a sequence of events. It is embodied in the figures (as an empty sign) and not illustrated by the figures (existing Idea). ${ }^{26}$ By this, Bacon paints for the act of 'action of perception' and not with the outcome or process of perception to the percepted. His 'intention' is for a "passible" phenomenal reading and not a universal understanding. Only within the phenomenal reading can Truth come to pass for the viewer. 

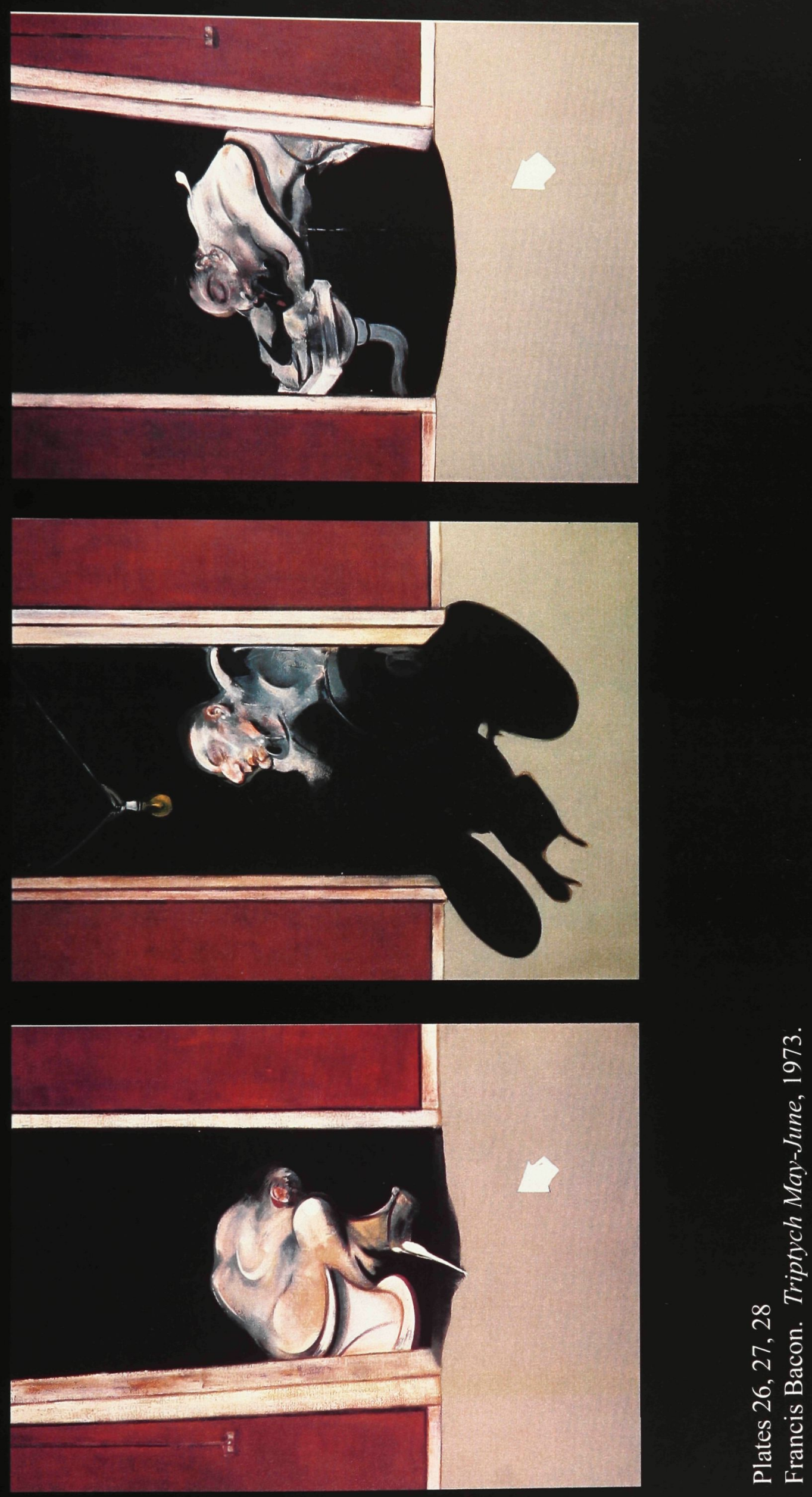

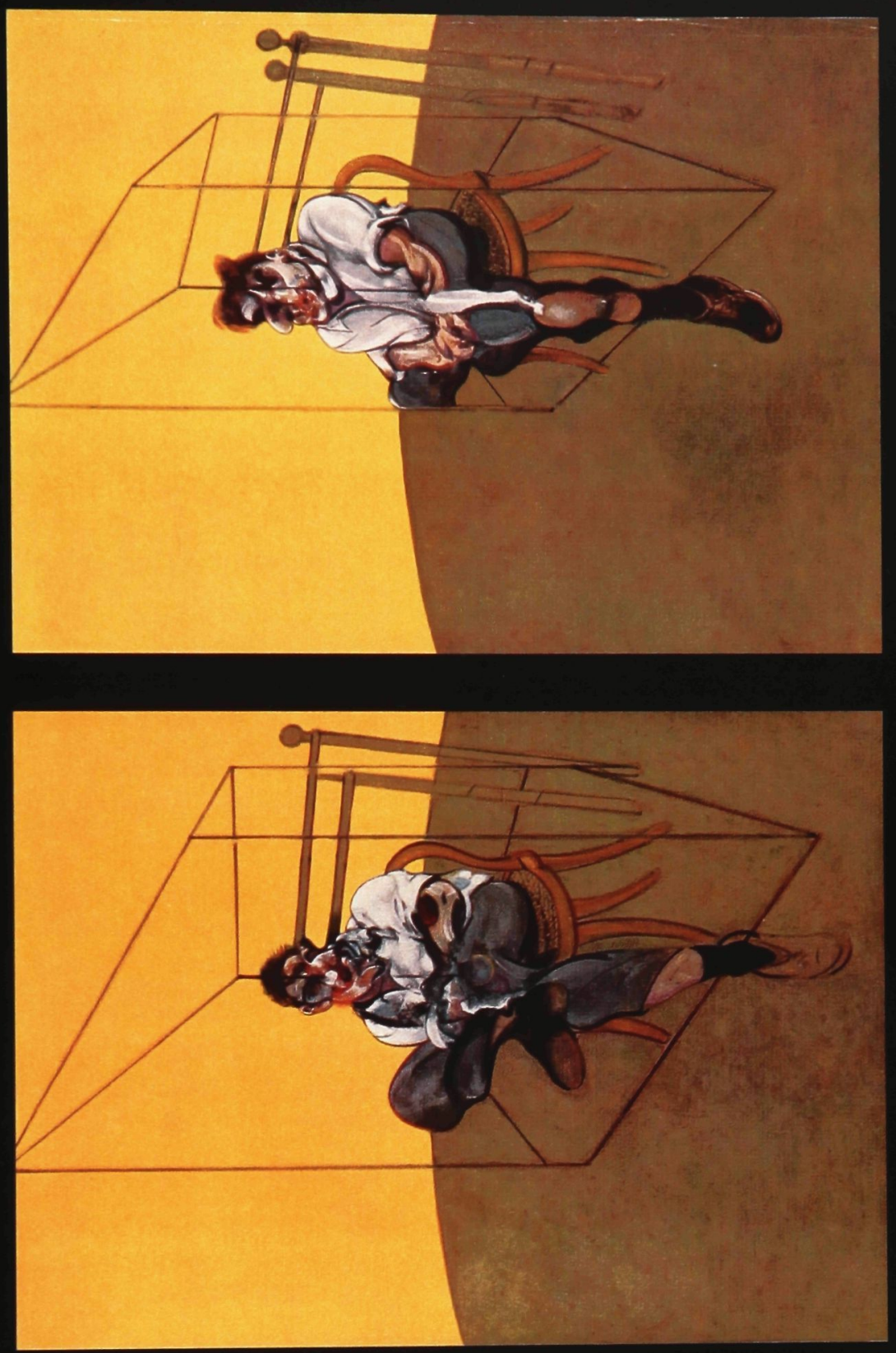

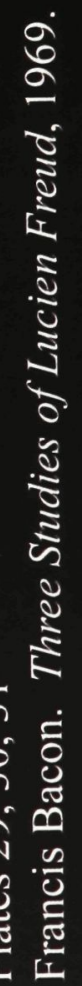


In the triptych piece Three Studies of Lucien Freud (1969) [pg. 46] the 'locus' has a very obvious relation to the phenomenal exchange. In each of the canvases, we see a figure sitting on a chair inside of a box located in a room. What is to be noted is the way the 'box' disturbs the figure. In most cases it divides the face of the figure in a very futurist manner (the turning of the head). The two sides of the divided face suggest different actions, a spasm, of invisible forces on the body as 'event'. ${ }^{27}$ If you look at all three together (which is literally impossible) we find that the two outside canvas figures are turned inwards towards the center canvas, potentially looking at the center figure. The center figure is however looking straight at us (the viewer). This may suggest that the three figures are existing together at the same time (whether it is three different figures or the same) and that not only they are aware of each other but also aware of the viewer. The figure becomes both subject and object interchangeably. When we catch the figure's gaze (in the center canvas) as subject (sign) respectively, we are within the "passible" - phenomenal exchange. We, as viewer, induce the split self, correspondingly, "to make sense of' the event as 'sign'. The 'figuration' (spasm, etc.) of the 'locus' prolongs experience (sensation) as we 'search for' (make sense of) via semblance into Idea in conscious present. The locus permits the eye to 'scramble within' the scene as event and prolong our interpretation.

This 'locus' (usually) takes the form of a figure as 'event' in Bacon's paintings. In most pieces, he uses a 'frame', which is represented, by a wire frame box that contains and gives boundaries for the event. This produces and 
divides two spaces within each canvas. The space of the locus and the space of the 'stage' (the environment or context, ex. bedroom). It is the space of the 'stage' in each of the triptych canvases that suggests narrative by apparent repetition of each. The details however pre-suppose even this. Refer to Triptych May-June (1973) [pg. 45]. The 'stage' space is not congruent or consistent and therefore can be understood as different 'stages' (in all three canvases) or the same 'stage' from different vantage points. If the first 'reading' is deduced (as it is as valid as the other reading) then all importance is removed from the 'stage' space and is given to the 'figure'/locus. It therefore acts as a frame for the locus, and as so is anti-space, rendering it equal to the literal (painted) wire-box containing the figure. The figure is therefore understood as one and the same figure acting in Time, preserved by Time and the frame/'box', as the visible boundary between 'locus' and 'stage', is unspace, a negation, or cut. The second reading suggests the opposite occurrence. That the 'stage' space is congruent and the same, making the figure different or non-existent as singular figure absent of Time. Therefore it is either 'locus' as all-Time in no-Space or 'stage' as all-Space in no-Time.

Either reading negate any Objective 'understanding' of a particular figure in a particular 'stage'. Thus, the narrative function (as suggested by the triptych presentation) is absent and the painting exists complete as 'end'. Bacon has been quoted stating that narrative is the by-product of painting that restricts the reading and creates the "boredom" of converying a story. "I do not want to avoid telling a story, but I want very, very much to do the thing that Valéry said 
- to give the sensation without the boredom of its conveyance. And the moment the story enters, the boredom comes upon you. ${ }^{, 28}$ Narrative is finite, it is the 'means to ends' of interpretation. It belongs to the exterior, it is 'exterpretation': Universal and exterior truth(s) that are deployed and adapted by/for the individual for the purpose of 'understanding' intentions (etc.) objectively, and as such, concealing one's Subjective/Concept by the World of the 'rational' and 'reason'.

\section{Conclusion}

The 'natural' process of contemplation is one of rationalism, 'to make sense of'. Meaning is believed inherent in all things. When we contemplate some thing 'constructed' by man we are inclined to believe that it was done for some purpose by some logical and rigorous means. 'Correct' interpretation usually consists at trying to understand the thing in the same manner as the one who created it. When the thing is 'explained' by the creator, we get a sense of relief from interpretation, we are all knowing now, no secrets. The understanding is the operational, applicable thought towards knowing, the Universal.

This 'reading' must be discouraged. Rationality must not be directed externally, it must be directed into the Subjective. Meaning is not inherent in 'things'. They are but signs. Meaning is only from within the self. When some thing is presented as 'end', as sign (empty, pre-perceptual), no 'means' is given, 
present or ever-within. The 'means' therefore enters the conscious mind as Idea as posited by Subjective/Concept. The semblance/resemblance 'function' of ideas by Concept is that which can be experienced/endured/revealed as/for self, internally. Exterior/Universal truths block this coming-to-pass action of the Subjective, therefore, all meaning consumed exteriorly is empty because it renders the self void.

Architects perpetuate this exterior reading. They constantly use words frivolously when explaining their work. Concept is commonly misunderstood for idea; phenomenological misunderstood for spatial-experience, etc. We explain our designing as process-based, as means to ends. Architects seem to encourage institutional classifications, belonging to movements/methods, adapting to technology and industry. Architecture is used as a 'response' to a certain condition or issues to be fulfilled.

Architecture as an act of will must be employed as something equal/same as the political and the philosophical, and not an application of such or a response to such. It must not adopt and transform to the new techniques of technology it must make technology adopt, transform and ever 'progress' to conform to the demand of architecture. This can be accomplished if architecture is created as 'ends' (as act) and not as 'means'. My thesis is to prove this notion the only valiant (pure) approach to or way of conceiving the creation of architecture.

The methodology to prove this is as follows. I will begin by creating the ends - the designed. I will suggest how this is to 'function' as such 
(Subjective/Concept) and I will illustrate how it begins on the path of the Objective by the natural traits of man by the "rational'. I will be exploring five rational methods that effectively offset the designed (and insomuch the individual's selfhood) into exterior meaningless. I will suggest how each one resembles a particular mode of 'architectonism' (method of thought by the architect within means as process of designing towards ends, ex. program, site, scale, material, etc.). These five rational cognitions under/and used for investigation are; metaphor, narrative, apostrophe, language, and intersubjectivity.

The Ends

To begin my architecture, I constructed the locus. It is the 'ends': from, and representedly is, the Absolute Subjective. At no part within Concept is it represented thought or anything architectful as defined as such. It is subjective, pre-thought, pre-conscious, pre-perceptual, pre-Idea.

The first 'action' was building the frame. A 4'-0" cube welded steel angle box. It was the 'cut' that defined the space of the locus. The second action was constructing by representing the locus. The Subjective entered into the conscious by way of making. In making and only through making can Subjective/Concept become sign for Idea by Other. Therefore no 'operation' was pre-considered, no form was thought-forth, and no means was employed for a 'logic' of making. Only through making was the Subjective revealed as 
representation by way of causation; material, scale, presence, and duration. The sub-conscious or automata did not drive the making/action; rather the drive was only by making/action in time by way of Subjective/Concept.

Refer to [pg. 4] for photography illustrating this object/sign. In the same manner as Bacon, the locus/sign is the representation of perceiving a series of sense occurrences/events. The figuration involved in the 'spasm' of the event is one that is not descriptive or implicit but rather exploits the pre-perceptiveness being as sign. The appearance of the representation/sign of the Subjective/Concept/act of making is not to suggest any thing 'architectural'. Implicitly, its Being is that only of/for sign of/for the potential Other to "make sense of' and to conceive of 'their' individual Idea for it. It anticipates the Other in a phenomenal exchange by offering a space of inversion to occur between contemplator and the designed. The 'space' of the exchange initiates the moment the Other's gaze comes into the object/sign's presence and enters as subject. The Other's selfhood is split into subject/object inversely corresponding to that of the sign (by/from Other). The space/endurement/passibility of the exchange is over/subdued once Idea of the sign is posited to the conscious mind as Idea, fully rationalized for/from the self.

The locus exists external to my (maker's) Subjective. It is for an-Other and no longer concerns me (the maker). The object can no longer reveal Concept or any thing insightful to me as what it is now. The making was the Concept revealed/endured/experienced but never consciously aware of/as such in the act. Its becoming is its Being, its justification. The locus/sign (designed - 
completed action) does not embody/reflect the maker. It is complete itself, as idea is for thought. For contemplation now belongs to the rational: to understand and think within the mind as science and reason. The 'ends' is no longer 'ends'; it now persists for 'means'/sign for the interpretation by another. There is no question of why or how 'this' became 'this' being, for it would only lead towards a quantified 'end' by thought-means and exterior post-rationalism. Because it was constructed by no 'means' it represents no 'means'; it is only 'ends'. An 'idea' was not represented; it was presented through representation. The other must make sense of it for themselves by/within themselves.

The method for this to occur is by rational cognition as thought penetrates the object/locus 'searching' for meaning and value for the act. The 'first' rational/reasoning occurs as the locus/sign is experienced in its entirety (as total object as 'one' sign). Form and content is 'given' (by an-Other) to it as an entirety. This is achieved metaphorically. This method is the manner in which the Concept presents Idea to the mind, by semblance and resemblance (metonymy and metaphor) with(in) the sensible past. The sign as entirety (not as/with pieces, aspects or parts), is the first Idea present to the mind by Concept. It is an 'immediate' metaphor with/for the pre-percepted sign to make it present to consciousness. This immediate or primary Idea is what is 'seen' at 'first glance' to the mind as an act of negation to 'register' some-thing outside the individual. The perceived idea of the object is deduced as metaphor of/for the sign. Therefore the sign is 'made sense of' by 'like or as' - something - in the individual's sensible past to be made accessible to the mind as Idea. A table, for 
example, is perceived of/as table because the Subjective/Concept has

metaphorically (via semblance/resemblance) presented to the mind the Idea 'this' table (from past Ideas within Subjective/Concept).

This 'first' perception (interpretation - metaphorically) corresponds to the 'first' act of phenomenal exchange. The negated Object is deemed (for contemplation) outside the individual and thus the 'space of inversion' is contextualized for a 'passible' experience of perception. When the 'passible' is not endured (or considered awry) the action is deemed 'justifiable' by the search for inherent meaning (content/form). This is the primary mode of 'exteriorizing' the self. As perception Objectifies the sign into Idea, the individual 'posits' meaning towards the object to 'justify' its presencing. The danger occurs when exterior 'meaning' supersedes the experiential. When this happens, Subjective/Concept is understood as the 'means' to understanding (ends) and everything internal is concealed and rendered mechanical, thus, itself meaningless.

\section{Metaphor}

In language, metaphor is used to describe a lesser-known thing in terms of a more recognizable thing. It is a symbolic substitution between things that can be explained by 'like or as' interchangeably. Metaphor is made up of two components: polysemy and ambiguity. Polysemy is the property of 'words' (in 
language) having more than one meaning and ambiguity (or equivocity) is the property of 'a string of words' having more than one way of interpretation. ${ }^{29}$

Metaphor (as language) is much more than a medium between the self and reality. It is even much more than mere language. Wittgenstein suggests that within the interconnectiveness of language, metaphor is a transcendence that produces a 'mystical' quality that exists beyond language's limits (what can not be said in discourse). It is with this notion that metaphor can act as the 'action of the phenomenal exchange'. Therefore the 'sign' that constitutes the Other within the exchange becomes simultaneous object/subject as deemed by and always in opposition to the individual contemplating.

The sign is revealed (metaphorically) in/by/to the self at two levels simultaneously: form and content, where content is inherently Subjective/Concept/Ends and form is Objective/Idea/Means. Refer to diagram below.

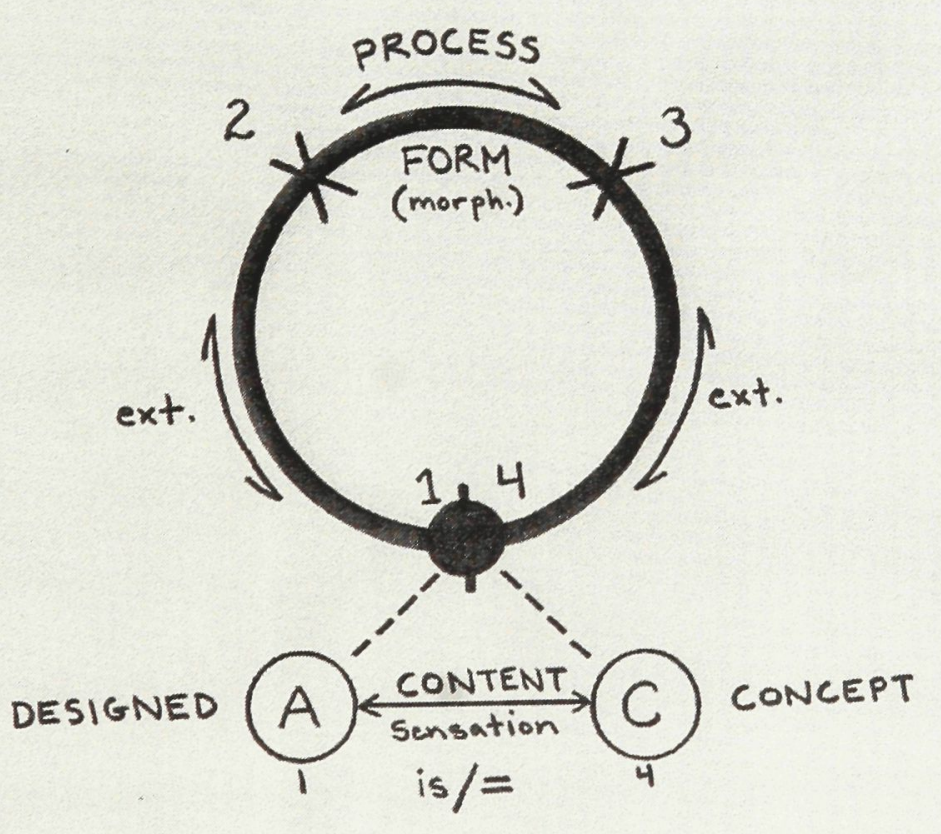


As the diagram suggests, form belongs to that which is Exterior, and dialectally, content belongs to that which is Interior. Content (situated in step $1 \& 4$ of the diagram) as posited from the phenomenal exchange, is what of metaphor exists for/as the 'passible' - endurement of/within action of semblance in/within the sensible past (Subjective/Concept). This is the space of the inversion acted dialectically between Subject and Object in both individual and Other (correspondingly). It is the 'feeling', sensation or phenomenal quality of the Other as sign which the individual metaphorically 'relates' to/with to understand and make conscious of. This sensational content is beyond language. We cannot experience the word 'pain', we can only experience the act of feeling 'pain' outside of conscious recognition which can be understood only after endurement to the conscious 'like or as' what/how 'pain' is to be felt. This is the complete and thus absolute 'process' of the Subjective. The true revealing in/by metaphor as 'ends' (something complete, Being for itself).

The content of the sensible in the sign, 'metaphorically' contemplated, exists as a 'half' (some un-quantitative part) of the 'sign as entirety' - for the internal-metaphor action/quality of Concept - the sensed becomes the sensible in thought by semblance (i.e. like/as) from what has been sensed. The other 'half' is form. The form is the exterior reading of metaphor that belongs and suggests 'means' (the rational). It is the why and how that consists in the 'to make sense of' reasoning that implies means to an end (or process-forth of/in thought). It is the linear (A towards B). In the realm of language it is what consist in language and not concerned with what is 'mystical' or outside of 
language. In visual metaphor, it is the visual identifiable process of morphing that connects and 'concretizes' the linear. In the diagram, the process from/between the 'polars' (architecture and concept) occurs by the form through 'morphing into'. The process is finite because it is 'means' and appropriates the 'end' for itself to exist. The poles are in relation to each other yet nonhegemonic and as such are interchangeable as origins. It can suggest a process from architecture to concept as well as from concept to architecture.

With this, form becomes dependent on content and content becomes dependent on form to function in exchange. Form appears most powerful because it tends to supercede the latter due to its obvious logic of process (Objectivity). The form can be easily represented to the mind as Idea because it can be (and insomuch is) objectified/externalized into language (etc.). Form being visually formative and sense/content being distinct and descriptive (relates to me as subject - experienced, yet undefinable).

This metaphor experience of the sign can be seen in Francis Bacon's painting Untitled (Crouching Nude) (1952) [pg. 58]. Here, the locus/sign (figure?) is staged before us to perceive. The immediate act of the eye configures the locus as something separate from the surrounding 'stage' space. Before the mind conceives the sign as something figural (content/form synthesis) the sign/locus exists in two 'halves': content and form. The content is what is sensed. The form is what it formally resembles (shape, etc.). In this case, (Objectly) the form is a figure and the content 'could' be (according to 


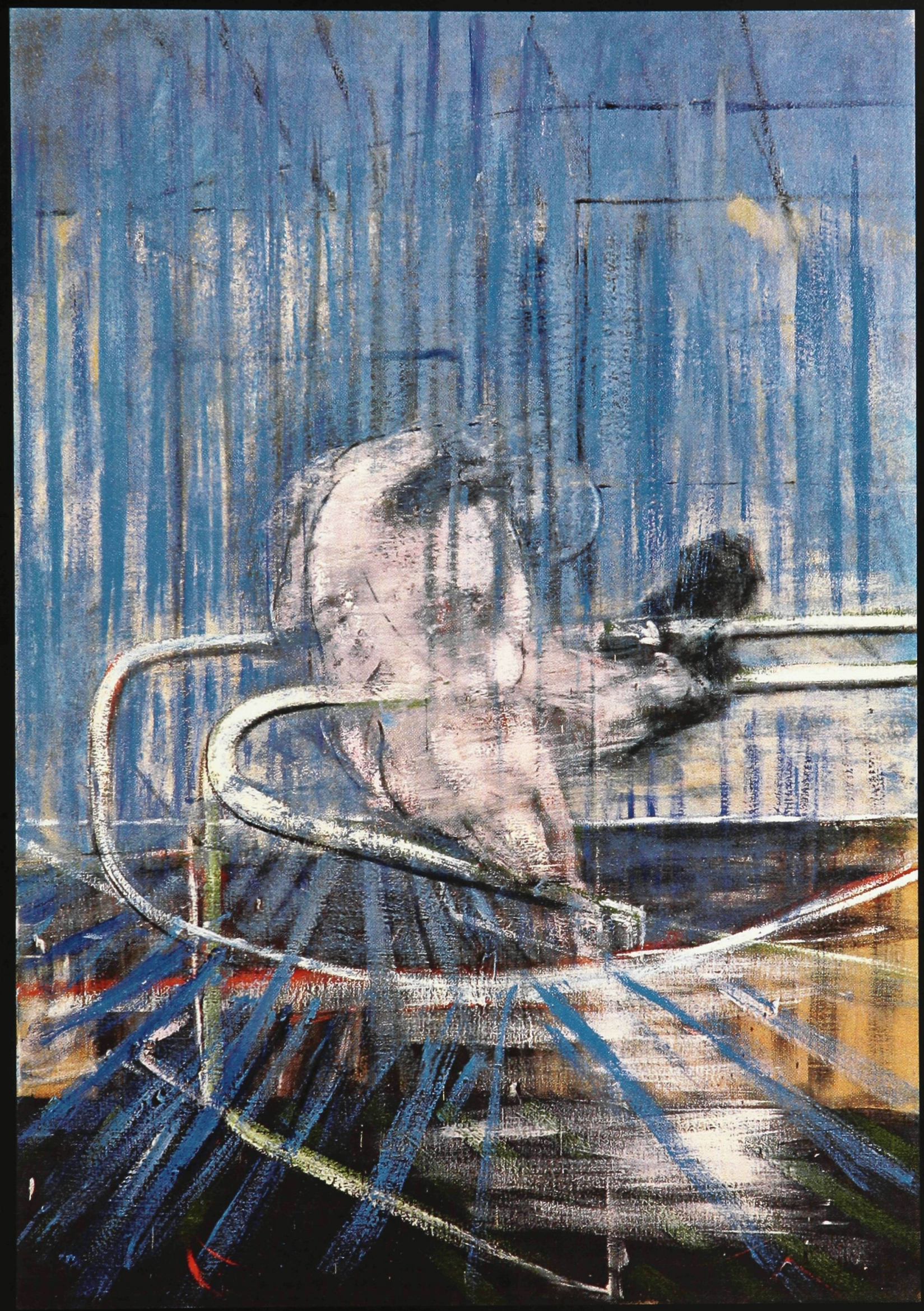

Plate 32

Francis Bacon. Untitled (Crouching Nude), 1952. 
me) solitude and torment (being aware that these words only represent what I feel and are not what I feel). When we configure this (form/content) 'we' (me Objectly) arrive at a 'tormented figure' (for example). I deduced that the sign/locus was representing a 'figure' because it resembled figureness, and I deduced 'tormented' because I related the visual sensation to something that resembled tormentfullness from my sensible past. The interpretation of the 'sign' (as whole) is perceived only when form and content are synthesized to the mind as Idea (single).

My Idea (tormented figure) is now concretely descriptive of my relation to the painting, and as such, it will remain for all consciousness this 'reading/interpretation' and nothing else. The Idea, as object, is exterior to my Being. I can recall 'why/how' I arrived at this interpretation/reading by using the form to express (explain) 'my' content deducement and use 'my' content to express (explain) the form deducement. I describe/explain my interpretation to another because it is external and quantifiable to me. The Idea cannot allow me to re-enter the Subjective/Concept. I can only rationalize to my 'self' the possible means to arrive at this 'ends' (the interpreted). Every time I consider 'why' I deduced 'this' interpretation I re-activate the sensible past as concrete Idea plateaus. The different Ideas I place before consciousness apply themselves metonymically/metaphorically in place of the previous. The structure is genealogical by nature (non-linear). When the sensible past is reinserted into consciousness the Idea exists sans Subjective/Concept and as such only replicate the initial Idea I re-evaluate. Thus, it externalizes my experience 
further and Ideas becomes dis-juncted forever restricting the revealing of the Subjective/Concept.

As Idea is object, it is susceptible to further exteriorization. An outside (Other's) interpretation or truth can supersede what I have given to it. I could adopt other readings to 'make' mine more "accurate", etc (Objective). This is the danger of Idea. The further we examine ourselves asking 'how/why' we deduced 'this' interpretation we are subsumed by the infinitenude of applying other Ideas (metaphorically in its place) in an attempt to enter our Subjective/Concept for Truth. The 'search' is as empty as the Idea(s) are themselves. Subjective/Concept is unconsciously active and is never reactivated.

To prove the emptiness of Idea and illustrate the existence of the 'sign as metaphor' split (content/form), please view my exercise (sign as metaphor, pg. 7). I have articulated the diagram with three illustrations. I started with the constructed 'end' - the designed (the cube) and took three photographs of one area (representing the entirety). The three photographs consisted of the same area from three different vantage points. This method corresponds to the manner of Francis Bacon's triptychs (the same locus in three separate panels). I then assembled the photographs together creating one 'scene' or event (the 'spasm' in Bacon's figuration, three figures comes to the mind as one and the same figure in Time). This completed step 2 of the diagram. For step 3, I took the assembled 'locus' and applied a method of formal morphology reconfiguring the locus as something else. All of the visual moves were 
dependent on the form of the previous image. What occurs is a reduction towards something formally objective by making (drawing in this case). The fourth step was then a complete formal deduction to something objectly visualized (a broken figure grasping a bat). The final drawing is what amounts as the form is reduced through the previous steps. I have called this 'end of process' the concept (as metaphor).

Here the concept is not Concept but rather Idea as over-arching Idea metaphorically implicit in all areas of the designed (potentially). In the traditional architectural methodology of designing (generally), the content is the 'theme' or "concept" (incorrectly termed) penetrating through the 'project' from (or believed from) the initial design 'moment' to the final designed end. This theme is the internal/exterior 'metaphor' contributed by the architect (etc.) to justify the work as "meaningful and rigorous". This exterior concept, Idea as metaphor (step 4), acts as a pole equal/same as the designed (concrete beginning and end of the system). Therefore, steps 2 and 3 act as 'means' to concept as end (the reduced designed in this case). What is to be noticed is the interchangeable direction between the poles. It can be read (as I have done), the designed acting as means to concept/Idea as end. Or, the concept/Idea can be the means to the designed as end. The formal morphology between the poles (step 2 and 3) suggest either/or but they do however concretize the use of 'means' and as such show 'process' of becoming as rational justification for the object's or concept's presencing. 
This process (step 1,2,3,4) is the exteriorizing force implicated in the use of 'means'. As the diagram depicts, the 'means' represents the big loop that exists out from/of the designed or concept (interchangeable) to arrive 'back' to the corresponding pole (the poles are equal and the same due to the interchangeable beginning and end suggested by form and the phenomenal synthesis experienced through content). The 'process' (the externalizing, represented by steps 2 and 3) can be an infinite number of 'steps' or plateaus. But as it acts as 'means' to some projected 'end', it is thus (pre)determined and finite upon application. In other words, once 'means' is employed, the ends has already been considered and pre-destined.

The reduction process method (ends to concept) or the increasing/complexity method (concept to ends) is equal and the same when 'means' is employed - an externalizing system. This Objective reading illustrates the 'form' of the metaphor as a process of morphing which 'controls' the outcome of the opposite end of the spectrum/pole. All 'steps' (depicted process) show/prove a 'logical' succession between/connecting the poles together. The Other (individual viewing process) can 'logically' configure the 'end' poles by formally constructing the method beginning from the other 'pole'. When we view the poles together (without the process of form, step 2 and 3) we are unaware of the objective/means/formal relation between them and what we experience is content. The content (feeling, sense, etc.) is inherent in both poles considered individually. When considered together, while recognizing a metaphorical connection, a synthesis of contents occurs in 
'search' for a balance of sense equality. Because there is no obvious/external/objective relationship, the only recognition (synthesis) that occurs metaphorically exists in the phenomenal exchange of perception. The mind (once knowing a formal/logical relation exists) re-configures the already perceived poles (as individual) into a balanced relation (unifying sense) synthesizing the two. One's original interpretation of the pole is re-interpreted to accommodate the existence of the other pole. Once a sense/feeling is synthesize to suit both poles equally, the metaphor is taken as truth and a concrete relation (the synthesized) exists as Idea. When this occurs it is impossible to perceive the poles individually without the re-occurrence/reconsideration of the Idea as synthesis.

There is no hegemony of poles until the notion of 'means' is implied. Together, the form and content of the sign as metaphor 'allow'/persuade the viewer to discard their own Subjective/Concept forged perception to an exterior - more rational - mode of interpretation as 'understanding'. The form of the metaphor acts as the 'means' or objective 'proof' towards the relationship between the two poles. The content is the re-active-phenomenal (the sense/feeling-synthesis) that the self creates in order for the poles to conceivably relate. The content needs the form; the form needs the content for the metaphor-system to be deemed a 'possibility' for understanding.

When architects use "concept" (over-arching Idea) as a design system they automatically pre-destine the future 'designed'. The "concept" becomes the 'means' in which the 'designed' becomes justified into presencing. When the 
designed is complete, the concept (initial seed of the designed) can be 'thread' back into process to 'logic-ize' its Being. This 'logic' is the dialectic between form and content. The conceptual process as 'formal morphology' describes the 'logical' connections between steps of/containing process (steps 2 and 3 of my system exercise). This acts as 'means' - formal 'moves' (reduction/constructing, etc.) - to the 'formed', the 'end'. The conceptual process as 'synthesized content' (when poles are considered together) describe the 'phenomenal equality' of the metaphor. The sense/feeling/etc of the concept as sign is combined into the sense/feeling/etc of the designed as sign. This synthesized content is what phenomenally binds concept to the designed.

An example, can be seen in my sign as metaphor 'system' [pgs. 5, 6, 8, 9, 10] When you view one of poles (the cube [the designed] or the drawing of a broken figure grasping a bat [the concept]) separately and unaware of the relationship towards each other, the phenomenal exchange that occurs between you (the viewer) and the sign will create 'Idea' of/for the sign (by synthesis of form and content from the sensible past: what it resembles formally and what sense/feeling/experience it resembles). When the poles are considered in a metaphorical relationship to each other (not yet aware of 'means' - what leads to what), the individual 'contents' are re-figured and reduced to find semblance between the two Ideas. The connection between the poles (metaphor) creates a new 'sign', one consisting of two separate (yet unrelated/foreign) Ideas. The viewer is 'convinced' of the connection when the synthesis of content exists as a new Idea. This Idea is then held in 'greater' regard than the individual Idea's 
gathered separately by phenomenal exchange from/within Subjective/Concept. What this suggests is that the 'rational' (Objective understanding) supersedes the experiential. This in turn corrupts and externalizes Idea further, concealing the self (Subjective/Concept/Truth).

When 'formal' (congruent/consecutive 'means') is considered into the system, the new Idea is externalized even further into a concrete universal truth/understanding (Objectivity). In my example, the formal belongs to steps 2 and 3. When the new Idea (synthesis of Ideas into a single shared content) is made aware of 'how' the concept has manifested itself towards the designed (formal morphology), a hegemony is created and a means to an ends is outlined. In my exercise, the 'ends' shows a progression towards concept. The process of formal reduction becomes a visual 'logic' that connects the 'ends' to the concept. Together, form and content, the metaphor 'makes sense' to the viewer and to the maker (architect) as well.

Because the 'concept' is external in its operation it has no inherent meaning contained within and can thus be metaphorically anything or nothing. Any concept could be 'made apparent' as a system of means for a single end to occur. By the fact that my exercise started with 'ends' and went through 'means' to concept signifies the inherent meaningless (or negative) system of operation. This supports the 'ends' as the only 'pure' expression/act/event of the Subjective/Concept.

What this whole exercise proves is that metaphor is implicit within everything perceivable. The internal metaphor is the action of phenomenal 
exchange within one's sensible past to present Idea to the consciousness. The external metaphor is a 'logical'/rational/objective synthesis (between poles of metaphor) that creates 'understanding' of the original 'signs' in a new way. This 'new way' is a derivative of Idea which is consciously 'applied' to the mind by quantifiable reasoning. This new derivative Idea is considered 'more accurate' and closer to the truth of the original 'sign(s)'. This is accomplished by configuring the formal 'logic' with the combined 'content' experience, which acts as proof to 'this' method of reasoning. The external metaphor is prevailed by Objectivity and thus 'stains' (or brands) the signs into Universalized meaning, 'protecting' it/them from any more individual/free interpretations. This is the danger of Ideas. They are externalized perceptions from the Subjective/Concept and as such can externalize even further from the self. This occurs simply because 'means' are inherently understood as a 'necessity' for designing. This 'means' (concept) is internally meaningless by the 'fact' that it corrupts the architect to design based on a system that is external to his Subjective/Concept and by the 'fact' that it corrupts the viewer/inhibitor to understand (potential) 'intentions and meanings' and not their own Subjective/Concept perceptions/interpretations.

Architectonically, metaphor is used as a design 'concept'. This concept (over-arching Idea) can be anything, which initiates 'means' to something, designed. It is seen as a 'root cause' (hence the notorious claim: 'concept') which becomes a structure and methodology which give rise to such critical terms as rigor, meaning, and even beauty. The 'worth' of the designed is based 
on this notion of an inherent 'conceptness' that 'exists' throughout its conception to its presencing as designed. This concept will forge things into a formal relationship between the designed and what is contained in the concept metaphorically. The concept can not exist as such if it is not illustrated formally. The content of the concept/designed metaphor is only present if the form of the concept/designed metaphor is present and perceivable as such. The existence of the concept is the existence of 'means' and as such removes and contradicts the individual interpretations into the realm of the Objective/Universal. If the interpretations of the designed are Objectified and therefore 'pre-dictated', the act of creating the designed is Objectified and created for a pre-determined end. Therefore 'rigor, meaning and beauty' can be seen as restricting, refining and justifying. We as the designers/architects are just characters within this system of 'means'. Our design decisions are reduced as the process processes towards the designed. Our role becomes diminished, as 'means' becomes ends. This by-product of the exteriorized self exists outside the concealed Subjective/Concept and becomes mere Object in the World, void of 'sign-ness'.

The 'sign' as metaphor can be considered the first 'movement' into the Exterior because it takes the 'sign as entity' (or an aspect metonymically representing the entirety) and is understood as the 'overall' (entire) form and content of the designed as single Idea and not in terms of 'parts of' a system of objects (Ideas). When the designed is considered as 'housing' (or containing) 
multiple signs, we arrive at the second 'move' towards the Exterior: that of narrative.

\section{$\underline{\text { Narrative }}$}

Narrative configures the designed into an undetermined amount of 'signs' constituting the whole of the entity. 'Narrative' here is a system of conducting/conveying a story as a series of events that exist outside of language. I am not interested in words or dialogue, but rather, visual 'signs' that allude to a possible construction of a linear and chronological reading of a string of occurrences happening in (contained inside or contained around) one place or entity. This can only occur when the limits and boundary of an entity is first formulated by way of 'sign as metaphor' as suggested from the last section (this is arguable and I will examine why towards the end of the section).

The conveying of a story can only be perceived as such if it is presented externally for someone to actively participate. In this way the story is Objective since it 'allows' for Others to enter and understand in a particular manner. Thus, the story must exist as a series of 'Ideas' and not as 'pre-perceived empty signs' or the story ceases to be a story that can/will communicate to those reading/participating. The story/narrative is a 'means' by conveying towards the conveyed (the end - the completed story/narrative).

The 'interactive' working of narrative occurs when the reader/viewer relates themselves to/within the occurrences of the story. The projection of 
oneself into the narrative is the power and privilege of narrative. This 'projection' of oneself into time and space (imaginary or real) is the action of the objectified self or 'virtual body-double'. This action occurs when an individual 'imagines' himself or herself as a certain character in the story or as the narrator itself. A relation makes the projection of the self into a different/foreign time and space possible to the self as object. Jacques Lacan describes this phenomenon as "the mirror stage": "the formative of the function of the I as revealed in psychoanalytic experience." ${ }^{30}$ This function of 'projection' of the self into time and space first occurs as an infant: when one is confronted with one's own reflection in a mirror for the first time;

"...once the image has been mastered and found empty, immediately rebounds in the case of the child in a series of gestures in which he experiences in play the relation between the movements assumed in the image and the reflected environment, and between this virtual complex and the reality it reduplicates - the child's own body, and the persons and things, around him." 31

Lacan suggests that once the child sees his own reflection and can distinguish it as something separate from the surrounding environment, the formation of the "I" occurs. The constitution of the self is dependent on the perception of self as Other. The now 'self as object' can deduce the notion of subject and individual self-hood. He (the child) now exists in the "Symbolic Order" or externalized Being. ${ }^{32}$

Once the establishment of the self as Object and Subject (interchangeably) is constructed and differentiated, the individual is able to project himself as object into time and space. With this, we (for example) can imagine ourselves 
in a possible future time and/or situate ourselves in spaces and places we've never been to (or perhaps have) in reality or fiction. This represented-self is the projected self is the externalized being. Our ability to understand stories/narratives is a function of this externalized-self. When we hear or read a story, an image appears in our mind of what the self-interprets/perceives from the depicted 'scene' (or whatever is depicted). The depicted scene is perceived to the mind via semblance/resemblance from/by the Subjective/Concept as Idea. If a character is depicted in the scene, we relate our self to the experience occurring to said character. We imagine the experience as seen through the character's eyes (first person narrative) or seen through the eyes of the narrator (third person narrative). This 'point of reference' is needed for a 'relation' (identification with an-Other) to occur between one's self and what is heard/read.

It is this 'point of reference' that 'allows' a reader/viewer/inhibitor to enter/project themselves as object within the system of narrative. This system, made up of all agents involved in the act of the narration, is called a 'fabula'. Mieke Bal defines 'fabula' as; “a series of logically and chronologically related events that are caused or experienced by actors." ${ }^{33}$ A fabula can therefore be considered a 'scene' comprised of agents acting in order to convey a narrative/story. These agents within the fabula/scene consist of all characters, all objects, the narrator and the individual for whom the narrative is conveyed for (e.g. the one reading). 
Since a narrative can only be conveyed by a singular point of reference at one instance (perceived from/by one agent at a given time), the term 'focalization' can be introduced into the fabula. Bal defines focalization as "the relationship between the 'vision', the agent that sees, and that which is seen." ${ }^{34}$ This 'vision' depicts the location of the host (the agent who is seeing/experiencing) and the location of the gaze (the agent seen/experienced by the host agent). This location (deduced by the host agent gazing and the agent of/in gaze) is the point of reference for the conveying of the narrative.

There are many types of 'focalization', but in this section I will only use and interpret two; internal focalizer and external focalizer. The internal focalizer is diagetically a character's (acting within the story) personal experience participating within the fabula/scene. This is usually considered as subjective or written in terms of the character's internal uniqueness and suggested individual mode of experiencing/interpreting. External focalizer is therefore a non-diagetic character such as the narrator. This is usually considered as objective or written from some being (the ultimate fifth-business) that sees all (ubiquitous/omniscient) without direct involvement within the place of actions.

When focalization occurs (in written form) by a character towards some 'thing', the reader submits his self for the character's self (subjective experience). The internal focalizor (character in contemplation of some 'thing') conveys their consciousness for the reader to relate to/with and insomuch comprehend the events of the scene. The comprehension is due to the inherent 
Objectivity of language, and as such, an Objectivity of thought (we think through language; our thoughts can be understood through language). The reader comprehends the act of the focalization incurred by externalizing himself in presence of the character (self as Other). In this way, the reader 'sees' through the eyes of the character, and as such, the character's will and subjective becomes accepted and transferred into the reader's. The character becomes a vessel for the exteriorized-self, allowing comprehension of the scene to unfold. ${ }^{35}$ This method of comprehension operates in a similar manner with the external focalizor also. The narrator (for example) becomes the vessel (point of reference) for the reader to deduce narrative structuring: an overall/objective 'view' on the scene as entity. The fabula as a system of narrative conveyance is thus complete.

The fabula, consisting of both external and internal focalization, privileges the reader to complete the system. He functions as the 'motor' of the story's conveyance, thus, gives Time to the system. Time is introduced the moment the reader externalizes himself into the fabula. Although the 'text' of the story is the 'means' of its conveyance, it belongs not to the story but rather inferred or constructed solely by the reader. ${ }^{36}$ In this manner, the believed Objectivity of the text becomes rather a linear string of 'signs' for the reader to interpret to himself. However, as a series of 'signs', the reader can be 'allowed' to perceive the conveyed scene differently than possibly an-Other reader. The 'allowance' of the text is due to the fact that it is a series, and thus a 'means' to the scene's conveyance. Therefore the text as 'sign' ceases to be an 'empty sign' and is and 
always was 'Idea'. In other words, the text in the conveyance of a narrative is Objective because it is the 'means' to an 'end' (the conveyed).

But, if within the scene (text) exists a 'possibility' of difference between the perception from one's self and that of an-Other, the Objective conclusion cannot be so concrete. Therefore, the 'empty sign' does exist within the system. It exists as 'word': The word/sign as metaphor. These 'signs' constituting the narrative (being linear and prescribed due to the manner and 'logic' of language) therefore cannot act in unison (or as connected parts of an entirety) but rather only as individual 'words' themselves. As singular, the 'word'/sign acts outside of Time due to its metaphoric relation to one's sensible past via Subjective/Concept. It no longer belongs to the system/series of 'words'/'means'/Ideas and therefore acts empty and only for itself.

The 'word'/sign exists outside of language and as such cannot be deemed a 'word'. The 'empty sign' is therefore a 'sign as metaphor' which participates in the phenomenal exchange within Subjective/Concept to be posited to the mind of the reader as Idea (perceived 'sign'). When the now Idea is inserted back into the system of narrative (language), the scene's entirety now exists for perception/interpretation as a system/series of Ideas. In such a manner, the scene as entirety becomes Objective and the story is conveyed in its prescribed manner.

For example, let's consider the sentence; The cold wind blew across the surface of the large flag on our neighbor's veranda. The conveyed scene described by the sentence is Objective because the image received within the 
mind (of all parties interpreting/perceiving) will be some form of what is the content (conveyance) of the scene. We can describe what the image in each of our minds is by vocalizing the sentence to each other. The conveying of the sentence has all parties imagining the conveyed scene, a large flag on a veranda. However, it is fair to say that we are all imaging different flags on different verandas. This occurs because the externalized/projected self takes the position set forth by the narrator (external focalizor) perceiving the scene. The projected self takes a point of reference from some 'location' where the self can comprehend the perceived scene described by the narrator. Therefore, because the different parties involved in the reading of the sentence are indeed unique and individual beings, the projected selves will assume different points of reference within the same conveyed scene. The time and space of the projected/externalized selves will be removed from this time (that of the reading) and exists in some Other time and space, again unique to the different individual's.

When we consider the words singularly and therefore outside of the structure of the sentence, we can further see the Subjective nature of 'sign as narrative'. Each adjective, verb, noun, etc will produce a different image of the word/'sign' perceived in each of the participating parties. The word as 'empty sign' exists for/within the phenomenal exchange and acts metaphorically within the sensible past by the Subjective/Concept. The Idea of the word/sign is therefore present to the mind and constitutes the imagined scene. All parties 
will arrive at a different 'Idea' of the word/sign due to the fact, again, that they are different parties and not the same.

What this suggests is that narrative itself is perceived as a series of individual 'signs'. Although the conveyed scene is Objective (means to ends) the words that comprise the scene are not. The word/signs are metaphorically linked to the Subjective/Concept of the individual comprehending the scene. The narrative is therefore an entity made/deduced from a series of metaphors. The parts (together as series) are the means to the scene's conveyance, and the narrative as entity (as conveyed scene) is the ends of the system.

Since the objective scene is 'conveyed' to the reader, the scene must have existed before the act of conveying. Therefore the 'means' of conveying the scene (although consisting of word/signs) remains pre-destined to some defined end. The end, being Object, (culmination of all existing 'Ideas' within the system of narrative) relies on the reader to project/externalize his self into Object or 'Idea-self' (virtual body-double). At what value is narrative when it needs and must function within the External realm of Being? A narrative does not permit the self to endure in one's Subjective/Concept but rather uses it as a means to produce an external-subjective (or 'Idea' self). As object, in the conscious mind, this external-subjective is malleable to further exteriorization, mainly by its functioning in 'relation' to/with an internal and/or external focalizor. What amounts is a conscious Objectivity of perception that solidifies the external-subjective. When the self perceives 'events'/scenes in relation to an-Other's, the formation of a derivative self-will is constructed, which 
becomes capable to exist Externally posited without reference to

Subjective/Concept. The internal phenomenal exchange is therefore an external phenomenal relation. The external-subjective is then comprised of intersubjects (further derivatives) rendering the true-self oppressed, negated and concealed.

To combat this exteriorization into the Objective/'virtual' realms, narrative must be re-considered if it is to be employed as a valuable act of perceiving/interpreting/comprehending. Francis Bacon discourages a narrative reading from his paintings because he believes it disguises what is really there. As I have mentioned earlier, Bacon is not concerned with a representation of a perceived sequence of events (a.k.a. narrative) but rather a representation of 'perceiving' as a sequence of events. ${ }^{37}$ Here, the attention is turned away from 'conveying a story' (narrative pre-exists - means to ends) and placed on 'telling a story'. Ernst van Alphen clarifies this difference;

"Conveying a story implies that a pre-existing story, fictional or not, is transferred to an addressee. Narrative is then reduced to a kind of transferable message. Opposed to this 'conveying of a story', 'telling a story' focuses on the activity or process of narrative [the sensation]. This process is not repeatable; it cannot be iterative because it takes place, it happens, whenever 'story' happens." 38

This "telling" of a story, in contrast to "conveying", suggests that the 'reading' of a perceived sequence of events is nothing narrative in itself.

Narrative is thus applied onto the canvases (by an agent, viewer, critic, etc), as a method of understanding "potential" objective meaning. If narrative is an illusion set-onto a system of events/scenes, then it can exist 'suggestively', 
without being applied 'means' to a conveyed 'end'. The illusion-narrative can be an 'end' into itself, sans 'means'. This "telling" of a story can thus exist solely for/within the Subject/individual.

If we return to examine Bacon's triptych painting Three Studies of Lucien Freud (1969) [pg. 46] as a non-narrative or illusion-narrative, we can see how the painting acts as a "telling" of a story. First, Bacon denies the traditional notion of a triptych (as a narrative of conveying a story) by use of the same character (the locus) in a similar manner/pose on each on the canvases. The repetition alludes to a 'possible' difference in Time. But since the three canvases show no evidence of consistent Time within the painted surface (same figure same space, different figures different spaces), the repetitiveness remains unresolved. The three canvases could be 'conveying' a single character in three different 'snap shots' of Time, or, the three canvases could be acting simultaneous in Time as three different characters in three different spaces. If we consider the latter, then the characters are sustained in Time by the gaze of the 'potential' viewer. He therefore acts within the system by initiating Time (as he is the external focalizor looking upon) and thus completing the 'fabula'.

This 'reading' (as non-repetitive, non-narrative) is reinforced by the individual character's (locus's) orientation in regards to the other two. On the left and right canvases, the faces of the characters are split in halves. The outside half is not addressing a potential viewer but rather attracted to something else and the inside half is gazing at the center character. The center character in contrast is gazing straight out from the canvas towards a potential 
viewer. The triptych is therefore non-triptych-esque but rather three separated canvases acting simultaneously with the viewer. When we view this 'system' together we see the entire 'scene' of the fabula; three characters who acknowledge each other and the potential viewer. ${ }^{39}$ When the paintings are seen in their entirety (together) it becomes the 'empty sign' which functions in the phenomenal exchange with/in the individual viewer. This is the "telling" of 'a' story. A story is not literally 'told' to us by something/someone else, it is perceived by/in us by/in the Subjective/Concept by/in the presence of 'Idea'.

The term 'told' is used in contrary to 'convey' because a story does not exist until a viewer acts within the system establishing the fabula. Therefore the narrative only occurs during the phenomenal exchange with/in a viewer. As the viewer embodies the role external-focalizor, his point of reference is himself in/as Time. He becomes the 'orchestration' of all events, perceiving them in free will, via the Subjective/Concept. He is not interpreting an-Other's interpretation, he acts solely for/as himself and as such becomes the 'Truth' of the painting.

The internal-focalizor (when one character is looking/acknowledging another) is collapsed by the fact that the existence of the 'other character' is formulated solely by the presence of a viewer. Because the content of the gaze (what is gazed, how, why, etc) is not conveyed by the characters but only alluded to a 'possible' gaze or illusion of gaze. The gaze is over-hauled by the presence of a viewer and the content becomes that of the viewer itself. For example; the central character (in the middle canvas) which acts as locus - 'sign 
as metaphor' - acts for/within us (the viewer) to deduce the content and form to the mind of what is perceived. When the outside characters on either canvas (internal focalizors) gaze upon the central character, no external point of reference is fixed/conveyed (we cannot see through their eyes), thus, their gaze is constructed from our gaze by way of what 'we' deduced as the Idea of the perceived (they see of the central character what we see of the central character). Therefore the internal-focalizor in a non-narrative system is void of priority and becomes equal and the same to the external focalizor.

Here is the division between 'sign as metaphor' and 'sign as narrative'. In Bacon's painting, the 'sign as metaphor' is constructed from the individual character acting as 'locus' in/for itself. This occurs when the triptych is considered in its entirety as one/same character/locus acting as subject and object (simultaneously) in all canvases outside of sequential Time. The 'locus' is a culmination of all three canvases acting together as one. The 'locus'/sign becomes Idea with semblance/resemblance of the viewer's sensible past within Subjective/Concept.

'Sign as narrative' occurs when the individual 'locus' is denied (as single) and it becomes three different characters/locuses acting in Time together with the viewer (the fabula). The 'sign' therefore becomes the act of perceiving all events/locuses equally but separately. The 'sign as narrative' is an illusion of concrete/objective narrative. He (viewer), as external (and only) focalizor, gives narrative to the system from his own perceptions via Subjective/Concept. Therefore a narrative reading is not conveyed from the characters (parts of the 
entirety) but applied onto from the 'telling' or phenomenal exchange acting 'within' the fabula.

It this way, Francis Bacon has successful denied an objective narrative reading of his work while at the same time allowing (giving the right to) the viewer for deducing their own narrative reading. This non-narrative system allows the potential viewer to enter into a phenomenal exchange/passibility willingly with/between the 'sign'. Bacon has therefore painted the 'ends'. A narrative reading occurs but by no Objective 'means'. There is no story within the canvas(es) to be conveyed. There is no 'method/way' to perceive the series of events presented on the canvas, only 'empty signs' which are representations of 'perceiving' as a series of events (Man is Time).

To understand how 'sign as narrative' is used as a way to design (or interpret a design of) the architectural object, I have visualized the method of narrativity for/of the designed. For my exercise [pg. 11], I have created a series of 'events/scenes' that resemble a string of vignettes in the form of a graphic novel. The intent is to allow a narrative to occur (by illusion-narrative) by way of subjective perception by an-Other. Since the 'designed' exists as ultimate 'sign' (for a metaphor reading, a narrative reading, etc) already embodied in its presencing as real-object, the exterior narrative (what is the exercise I will now examine) will be considered a 'potential' objective reading. As the 'sign as metaphor' exercise has established in the last section, this exercise will again exist subordinate in principle to the 'original' interpretation gathered from the sign as entity alone. The illusion-narrative quality of the exercise allows for a 
subjective reading but will still 'apply' itself un-naturally to the 'designed' when it is re-considered in re-contemplation. Therefore, as the narrative exercise is 'corrupting' the Subjective/Concept by its very existence (by giving boundaries and limitations, however undefined they appear), it does and will secure the designed's Being as something architectural in essence. It is in this manner that the narrative reading is valuable in designing and in interpreting the designed. Since narrative 'allows'/needs the viewer to externalize himself 'inside' or around the designed object, such architectural notions as scale and internal spaces are suggested. The narrative reading will comprehend the designed as containing parts or spaces which make up the designed as an entirety. By allowing a narrative to be 'told' and not conveyed (by the use of an illusion-narrative) the 'story' unfolds as deduced in/by the viewer/inhibitor by free will. Therefore, the narrative exercise, though exterior to the designed object, (because it supplements the Subjective/Concept perception of original sign for an 'Idea' by re-perceiving it with sign as narrative in mind, and because it requires the exterior-self to operate) will suggest how designing as 'process'/means is that of 'conveying' a story (the Objective/Universal) while designing as 'ends' is that of 'telling' a story. This gives authority to the one viewing/inhabiting/interpreting (Subjective/Concept) under a set of rules and guidelines that are themselves only suggestive, not concrete.

I began the exercise (sign as narrative, pg. 11) by considering 'the designed' in its surrounding cube structure. I grided the sides of the cube into 6 equal rectangles, vertically oriented (dimensionally resembling that of an 
approximate 11 " x 17" paper size), which three-dimensionally divided the cube into 18 equal three-dimensional rectangles or 'bricks'. These 'bricks' represent locations or parts of the whole. I then photographed each of the 'bricks' from different points of reference that enabled the surface of the image to contain/show most of what was contained in the 'brick' (as a part of the entity). These were photocopied to a workable size, 11" x 17". By randomly choosing a photocopied 'brick', I began to 'carve'/draw upon the image to suggest 'scale' and the possiblity of a 'scene/event'. Each image-'brick' was worked upon individually and independent of the previous or forth coming image-'brick'. Once all the 'bricks' were completed (when a possible scale and possible space/event/scene was suggestive) they were arranged in a linear fashion on a wall. The placement was not dependent on each other in this image-form or by their original position as 'bricks' in the entity, it was rather based on a suggestive non-narrative (possible) 'readability', in short arbitrary.

In each of the image/bricks there appears a re-occurring figure, a man with sunglasses and beret. His role is to suggest time and scale to the system. By creating the same character in 18 or more different spaces/scenes I have introduced a possible conveyance of a 'pre-existing' narrative. The character is seen as 'travelling through' a series of spaces/scenes that consist as 'pieces' of a whole. This is of course how it was constructed, 18 'bricks' of a whole. Within this narrative system, there is an internal-focalizor (the character) and an external-focalizor (the camera/artist and potential viewer). The viewer must then externalizes himself into the fabula to possibly 'comprehend' the scene. 
He can at once relate himself to/with the character's point of reference and to the camera/artist point of reference (the image as an entirety). What amounts when considered in this manner is the means of conveying an end. It would be in this case, the total or complete image (as narrative): when all images are perceived in linear progression to 'receive' an Idea of the totality. Therefore an end is pre-destined from the beginning.

In this narrative reading, the system (linear, successive, irreversible, etc) is suggestive of conveying a story. The 18 pages act together to create a diagetictime (that of the images/narrative) which the viewer can trace a path (or movement) through to deduce an 'end' (the conveyed). The graphic novel is therefore a means of interpreting the ends (the designed), and as such, hegemony is introduced into the system. Through this super-imposition, the graphic novel is considered a 'revealing' of the truth behind the 'designed's' becoming. In such a manner, the narrative is thought of as existing before and thus for the designed. The designed must therefore embody the narrative that it is considered born-from.

The 'designed', through the narrative interpretation, no longer exists as 'sign' and becomes 'Idea'. Narration becomes then a mode of Externalizing. It functions as an outside rationalizing system that is applied-onto the original 'empty sign' giving it meaning from someplace other than within its presencing as object. As narrative relies and needs the interpreter/viewer to externalize himself to enter the fabula (via internal/external focalizors), the narrative (graphic novel) becomes a visual 'guide' to consider the designed as an 
architectural object which 'contains' these spaces/scenes depicted. When all 18 pages are viewed consecutively (first to last), the 'movement' within the depicted images correspondingly confirm a 'movement' within the 'designed'. In such, the narrative (which is for the external-self) is itself an exteriorizing system that re-configures the 'designed' into something of 'its' making. Scale and internal spaces (potentially) are deduced for the designed by/from the graphic novel. In this, the 'designed', being deemed an architectural object, is considered a representation of 'something' and not 'something' in itself.

When a story/narrative is conveyed to a viewer/reader, he becomes absent from the system as 'himself' and can only enter as an externalized-self. As such, the narrative and the 'designed' become exteriorized also (a means to an end) and an Objective interpretation conquers the system as truth. The viewer is thus a spectator who stands passively 'outside' this already pre-existing system unable to exercise free will.

When belief of a means or pre-existing truth is removed from the narrative system, an Objective/Universal reading is not inherently embedded within. This suggests that the narrative structure/reading was an illusion in the first place. Since, in my exercise, there was no objective/concrete narrative from the beginning and there is no objective/concrete narrative implied in the creation of the graphic novel, there could be no narrative at any time 'within' the system to be conveyed to a potential viewer. The system is therefore non-narrative or illusion-narrative. When this is considered the initial examination is reconsidered. The character within the image can no longer be considered one 
and the same; he must exist metonymically as a 'condition' of human interaction. The 18 pages can therefore be seen not as 'successive' or 'linear' but rather existing together simultaneously for interaction with a potential viewer. Thus, Time is not embodied in the characters but only within the active perception of the viewer, which completes the fabula. ${ }^{40}$

When the pages are considered equally valid in time, no hegemony is deduced and the narrative reading as a conveyed story is no longer. There is no beginning (means) and no ends to the system. The internal-focalizor (the characters) is no longer valid as a relation outside the viewer's self. The external-focalizor and the internal-focalizor are equal and the same since it is the viewer. The viewer's point of reference becomes that of his own Subjective/Concept and the external-subjective or exteriorized self is no longer needed/required.

As each of the pages act equally autonomous to each other, the individual image no longer portrays any sign of narrativity embedded within. The image is therefore perceived as a 'sign as metaphor'. The scene/space of the image metaphorically relates to a possible perceived scene/space within the viewer's Subjective/Concept, thus a phenomenal exchange occurs. The viewer 'makes sense' of the scene/space by formation of it as 'Idea'. The character in the image does not relate to the viewer by the creation of an exterior-self, but rather only adds to the scene/space by alluding to a possible scale and figure ground. The character 'allows'/gives rise to the perception of the scene/space to be some architectural 'Idea'. Refer to the diagram below; 


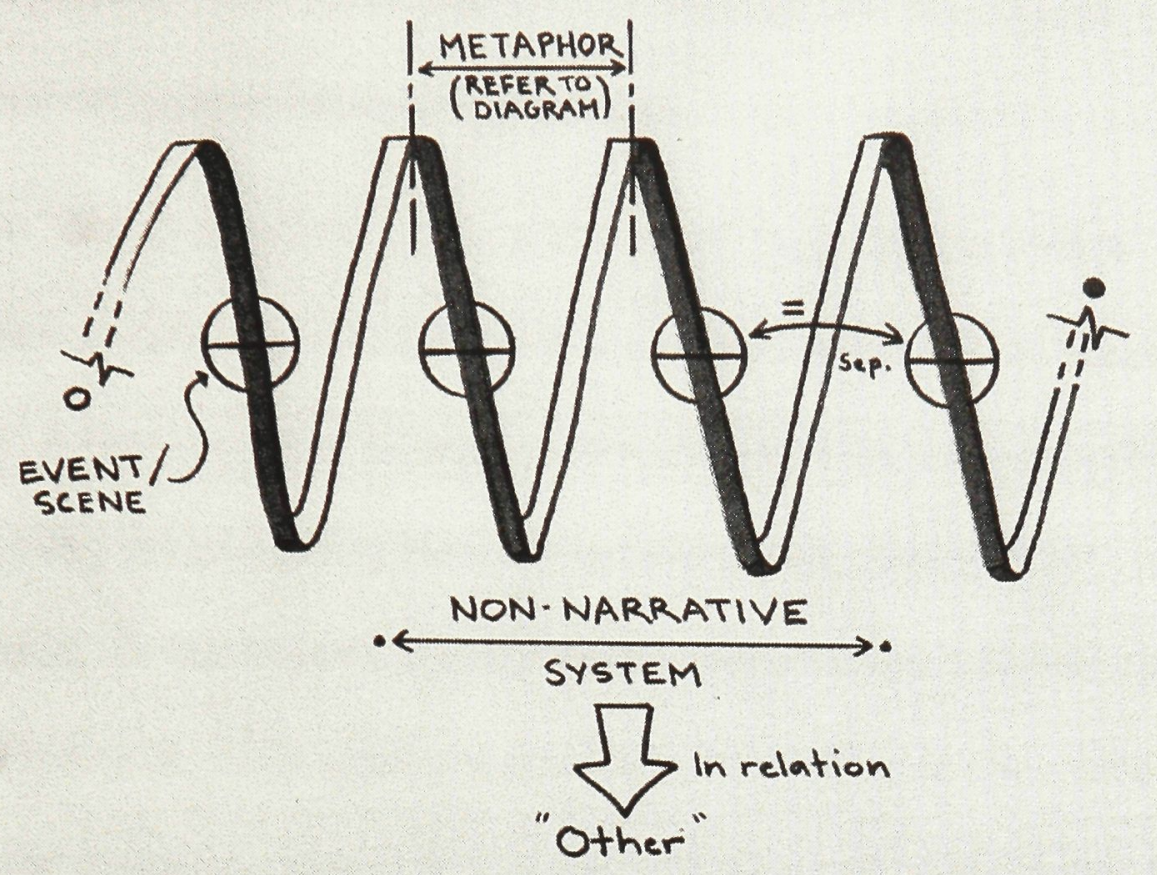

As the diagram suggests, the 'points' on the spiral are the pages of the graphic novel, which act separately and equally as 'sign as metaphor'. The spiral itself (made up of all points) is the 'sign as narrative'. After all 18 pages are perceived separately and equal as 'sign as metaphor', what remains are 18 'Ideas'. It is these contemplated together that constitute 'sign as narrative'. Being non-narrative itself, the sign exists as a total and complete system and as such is the 'ends' (sans means). The sign is constructed of 'Ideas' (18 of them), and as such, has a boundary and limitation and thus is not 'empty'. In this way it is similar to the 'concept' as mentioned in the last section which was used as an over-arching Idea as manifold that was metaphorically 'represented' throughout the entire process from beginning to end. Within this 'concept' was content and form which became the 'logic'/means that related all parts together. The 'concept' was not 'empty' due to the processing aspect of its 
intention/purpose. Its process restricted the concept, and the concept redistricted the process (ultimately the ends).

The 'sign as narrative' is also restricted by its processing from a culmination of different but equal (non hegemonic) 'Ideas'. The 'sign as narrative' is thus corrupted as such. A possible narrative reading can be deduced but it is restricted to use each and every Idea equally for its construction. In this manner, the sign as non-narrative is a complete system with and for itself. Only when it is considered in relation to some thing else (mainly the designed - sign as entity) that it becomes narrative by causation. Therefore the pure 'sign as narrative' existed only within the designed object (the ends). When the mind first contemplated the 'sign as entity', the parts were considered as pieces of a whole. The narrative reading came as a perceptual undertaking comprehending the connections (etc) with the parts/pieces in comparison to the whole. The exterior-narrative (the graphic novel) gave the designed 'context', making it a representation of a potential architectural object. Scale was introduced, and program was suggested, and now the 'sign as entity' exists as something deemed architectural.

Narrative and non-narrative systems are thus equally invalid as potential methods of internalizing the experience of the 'designed'. They both 'corrupt' the 'designed' into being a representation of some 'thing'. Whether it is a series of consecutive moments through diagetic time/space (sign as narrative) or a system of separate/equal events/scenes outside of diagetic time (sign as nonnarrative), the result is ultimately the same. Narrative needs/requires the 
externalized-self to operate, while non-narrative requires that the self reperceive what has already been perceived (narrative as a system of 'Ideas' that together constitute sign). They both act as 'processes' that (directly or indirectly) corrupt the original perception of the 'sign as entity' first perceived from the internal Subjective/Concept. In this manner, they are both meaningless.

The question of whether or not 'sign as narrative' or 'sign as metaphor' comes to mind first is impossible to secure due to the fact that the interpreter has no 'fixed' point/space/context of contemplation. The answer is secure when the intrepreter's point of reference is secure. If for example, we consider Giuseppe Arcimbaldo's (1527?-1593) painting Earth (1570) [pg. 89], it would be impossible and irrelevant to deduce if the painted image is first perceived as an entity (face) or as parts (animals). However, what is relevant to note is the fact that both are needed (interchangibly) to perceive the painting for what it is. An optical balance occurs between both the overall form and the collection of objects within. When the eye focuses on only one, the other disipates into a sort of ambiguity. If sign as metaphor is contemplated, the form of the face and the content of its character is deduced. If sign as narrative is contemplated, the different types of animals are deduced. Only together does the painting reveal and create the 'effect' granted by the artist.

This refers to the 'designed' in a similar fashion. In the ordering of this text, I suggest that 'sign as metaphor' is and must always be considered first, but it is due to the relative size of the real-represented object. In this case, the 


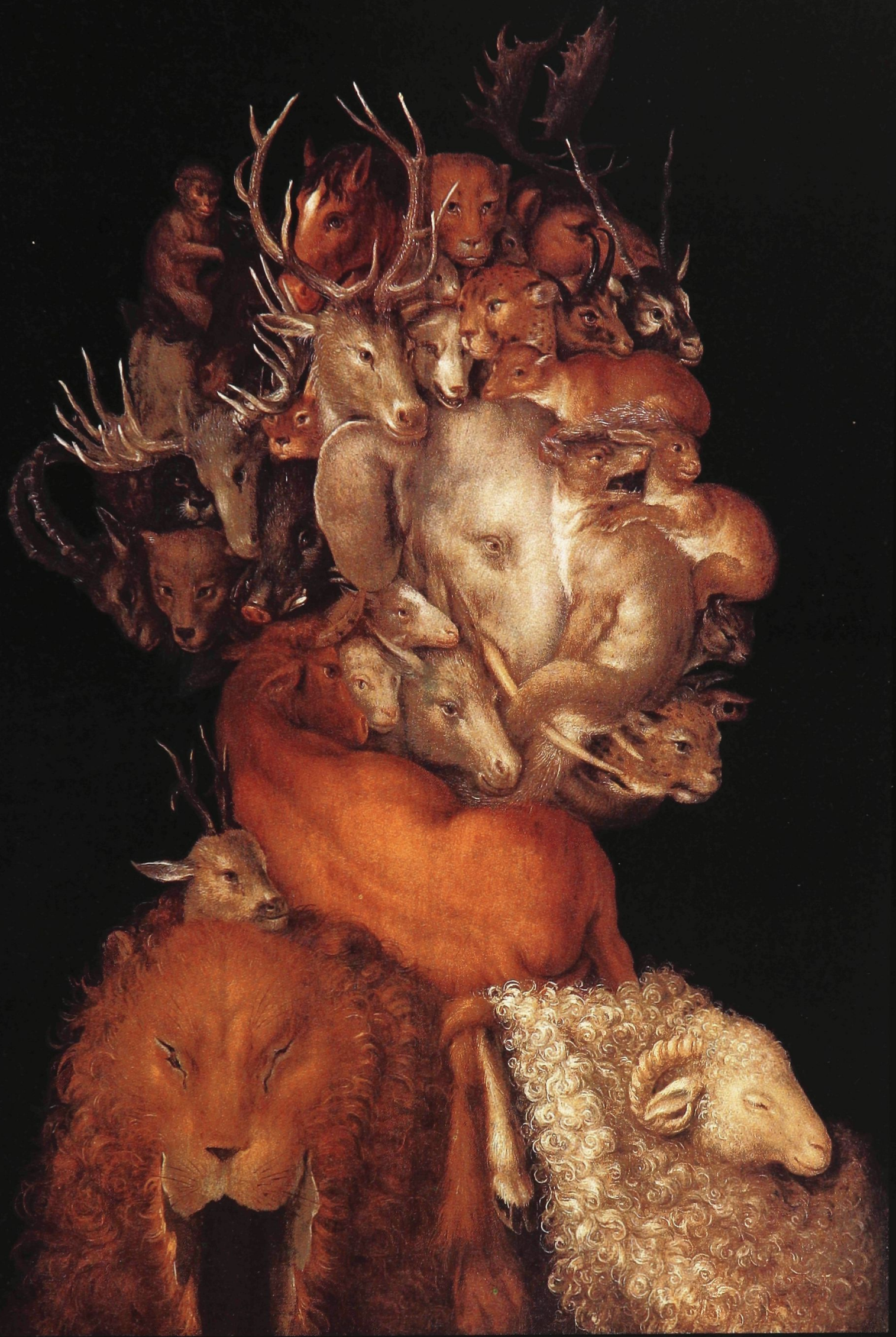

Plate 33

Giuseppe Arcimbaldo. Earth, 1570. 
object is a cube 4'-0" square so at first gaze/contemplation it is seen as entirety first and pieces/parts second. The ordering is not concrete for all signs as entities; it is conditional on the individual reference point of the viewer/inhibitor.

When 'sign as metaphor' (as entirety) is considered the first 'movement' into the Exterior, 'sign as narrative' (as parts/pieces) becomes considered the second. The third 'movement' into the Exterior is 'sign as apostrophe', the allencompassing visual-sign.

\section{Apostrophe}

Narrative fails (as a revealing of the Subjective/Concept) because it is considered in relation to some thing else, outside of its own Being and outside of the viewer's Being. In my previous exercise, the narrative and non-narrative systems arrive at the same point of external/Objective 'meaning-less'; thus they are considered a process towards some thing as 'ends' or considered a nonprocess towards post-rationalizing a pre-existing end.

The 'sign as apostrophe' occurs as/by the occurrence of 'sign as nonnarrative' (when the 18 pages act separately and equally together with/in the individual viewing). The apostrophe disrupts the circuit of communication, which ultimately disassociates the relation of the narrative to the 'intended' addressee. ${ }^{41}$ In this way, apostrophe is the triumph of narrative. I am using apostrophe here as it is considered in poetry and not as a symbol that 
replaces/omits a text-character or to connote possession. Poets use apostrophes to serve as intensifiers to images of invested passion. "To explain its meaning by treating it as the natural effect of an unexceptional cause" 42 or "to call it into being by asking inanimate objects to bend themselves to your desire." ${ }^{43}$ Below is a portion (stanza VII and VII) of the poem entitled Among School Children (1928) by William Butler Yeats, which is an example of such apostrophic poetry;

Both nuns and mother worship images, But those the candles light are not as those That animate a mother's reveries, But keep a marble or a bronze repose. And yet they took break hearts - - O presences That passion, piety or affection knows, And that all heavenly glory symbolize - $O$ self-born mockers of man's enterprise;

Labour is blossoming or dancing where The body is not bruised to pleasure soul. Not beauty born out of its own despair, Nor blear-eyed wisdom out of midnight oil. $O$ chestnut-tree, great rooted blossomer, Are you the leaf, the blossom, or the bole? $O$ body swayed to music, $O$ brightening glance, How can we know the dancer from the dance? ${ }^{44}$ [ Italics mine]

The apostrophic component occurs/resides from the fifth line of the stanza through to the end of the last (the italic type, similar in each). The apostrophe is the 'O' and the ',' which acts lyrically (phrase-like: as it would appear/sound in discourse). The apostrophe apostrophizes the word/noun that it precedes. This word/noun is called a 'vocative'. For example, in line 5 of latter stanza (VIII), the apostrophe (as symbol) is the ' $\mathrm{O}$ ' and the vocative is the "chestnut-tree". 
The poet (by his use of apostrophe) calls-upon the "chestnut-tree" to act as a signifier to something potentially 'divine' (who/what the poet summons as he calls upon the object). The "chestnut-tree" is therefore not 'a' or 'some' chestnut tree but rather a symbol or metaxy towards something 'larger' and more mystical (divine spirit, God, etc). As such, the chestnut tree operates as a metonymy to allude to something that is embedded in the whole (what is truly called upon by the use of apostrophe). The poet is attempting to 'communicate' a feeling/sensation (human, from his self) with some 'thing' mystical that resides metonymically symbolized by/as the "chestnut-tree".

The apostrophic method suggests that the poem was written (and to be read) in a lyrical manner (by means of discourse). The lyric's (the poet's) intention was not to be heard (not directing the poem to an audience), but rather overheard, thus directing the poem to/in himself (as poet) or to some one/thing else (divine). It is not directed to/for the listeners. ${ }^{45}$ The poet calls-forth the mystical to communicate a feeling/sensation he has experienced (or is experiencing) in a medium (metaxy, metonymy, establishing a relation to) that which is a kin (or belongs) to the mystical. The poet is therefore trying to identify with the mystical by allowing the mystical to identify with himself (metonymically). ${ }^{46}$

The vocative, thus, is a device of the 'poetic voice' to metaphorically relate object(s) to establish the 'Idea' of self. The object is therefore invoked as subject and as such relates its being to the provoker (the poet). Thus, invocation is a figure of vocation. ${ }^{47}$ The apostrophe attempts to reconcile the 
subject/object internal dialectic by constituting a metaphysical-relation between both subject and object (the self and an-Other) simultaneously configuring them as metonymically equal and the same (it metaphorically reflects my self, I metaphorically reflect it's self). What occurs now in the system is a subject/subject relationship. Therefore the relation is void (being one and the same). In this way, an 'Idea' (perceived object) can become immaterial and transcend its Other-ness or relation-ness with the self-subject.

Apostrophe is therefore an act of changing/transforming objects into subjects, and in short, changing them into 'ourself' ${ }^{48}$ The 'Other' is a result of actions metonymically signifying the internal-self. The internal-self is, through procedure (of writing, making, etc), metonymized for the event of all selves. ${ }^{49}$ Within this Solipsist inter-universe, the exterior world is deduced to metonymic-fragments of self that act as 'empty Ideas', un-perceivable, indecipherable, non-signs. The words 'I, you, they, etc' are not 'signs' depicting a difference in assembled 'Ideas' but rather mere marks employed to depict a difference in the state of the poet's mind. ${ }^{50}$ In this way, it works against narrative by denying sequentially, causality, time, teleological meaning, etc. $^{51}$

"In lyrics of this kind a temporal problem is posed: something once present has been lost or attenuated; this loss can be narrated but the temporal sequence is irreversible, like time itself. Apostrophe displaces this irreversible structure by removing the opposition between presence and absence from empirical time and locating it in a discursive time. The temporal movement from A to B, internalized by apostrophe, becomes a reversible alternation between $\mathrm{A}$ and $\mathrm{B}$ : a play of presence and absence governed not by time but by poetic power. ${ }^{, 52}$ 
The poem, drawing, etc, is reduced to a timeless present, diagetic to the act of its creation. The 'objects' (metonymized subjects) depicted in the poem (or other medium) have no inherent time of Being. The apostrophe disassociates the object from the Real to refer solely to/of the subject - the writer's self. This atemporalness is (refers to) the time of the discourse (the lyric) rather than the time of the story. The lyric is thus in a state of selfreferent 'now-ism'. This 'now' is thus interpreted as a 'potential present', and as such, activated by a potential reader. The reader, upon the act of reading, uses this 'now' as a point of reference for his role 'to act'. He then 'assumes' the role of poet (or exteriorized self). The reading of the poem is, however, denied to the reader. As the lyric is 'over-heard', the poem exists hermetically for the poet and not for a potential recipient (reader). As the poem exists as a series/system of 'empty-Ideas' (the metonymic poet-self) the poem is not 'allowed' (no permission) to be perceived as something perceivable. The poem is therefore not for the self or the exteriorized-self (as reader), but itself exists exteriorized and un-penetrable. It exists as 'end' in itself for itself.

In my exercise, 'sign as apostrophe' (compact disc-not included), I have created a system of apostrophe in the medium of video. The intention was that of apostrophic poetry: to create a non-narrative presentation that destroyed the 'sign/locus' into being 'external/empty-Idea'. This was achieved by reevaluating the structure of the non-narrative system. Instead of considering the diagram as a spiral (or corkscrew) with points that were delineated (due to the separate and equal non-hegemonic system that resulted in/as each page of the 
'graphic novel'), it was first considered as a spiral (or corkscrew) with 'random' occurring points. These new 'points' could not be formed as a result of metaphoric semblance because they exist outside the system of phenomenal exchange.

By choosing points on the 'outer ring' (which acts as the process from means to ends; see metaphor diagram pg. 55), the points are now located as 'instances' of the act of perceiving (as sign becomes Idea to the mind). As this is the internal function of the Subjective/Concept with/in one's sensible past, the instance the sensible past becomes conscious to the self, as such a 'function', it ceases to be 'processive' (due to the lack of Subjective/Concept) and becomes a genealogy of previously formed 'Ideas'. Refer to diagrams below;

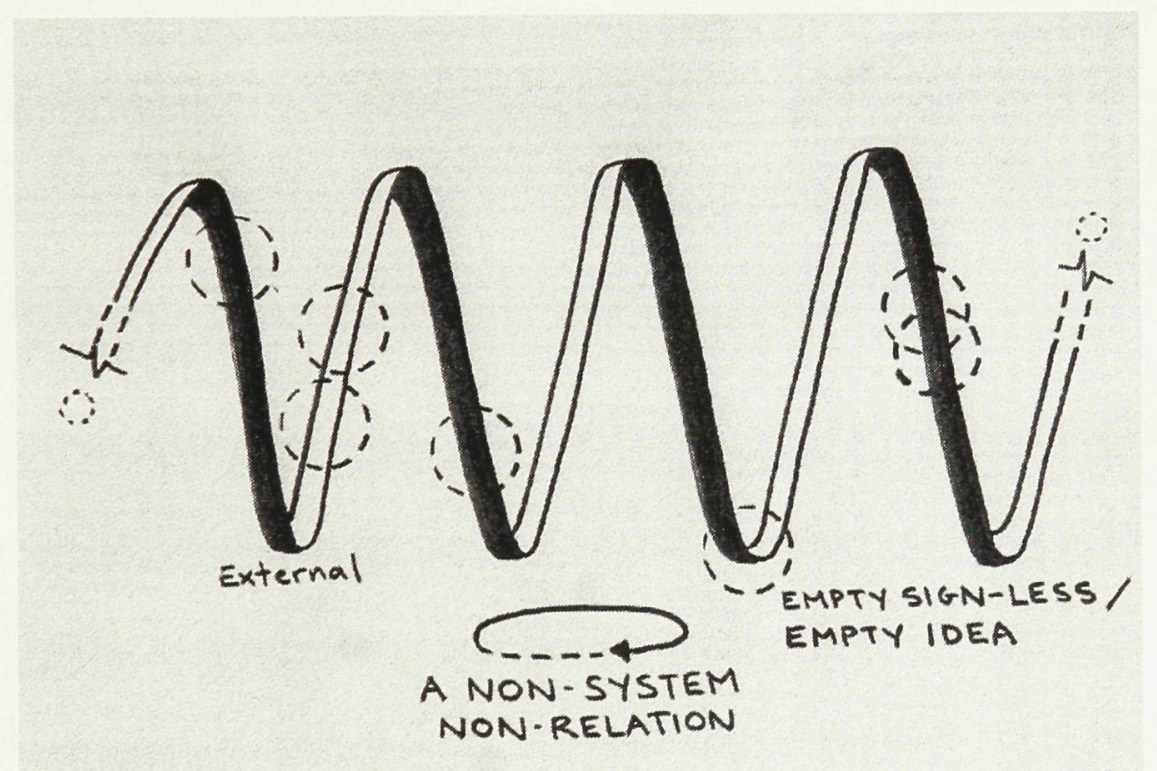




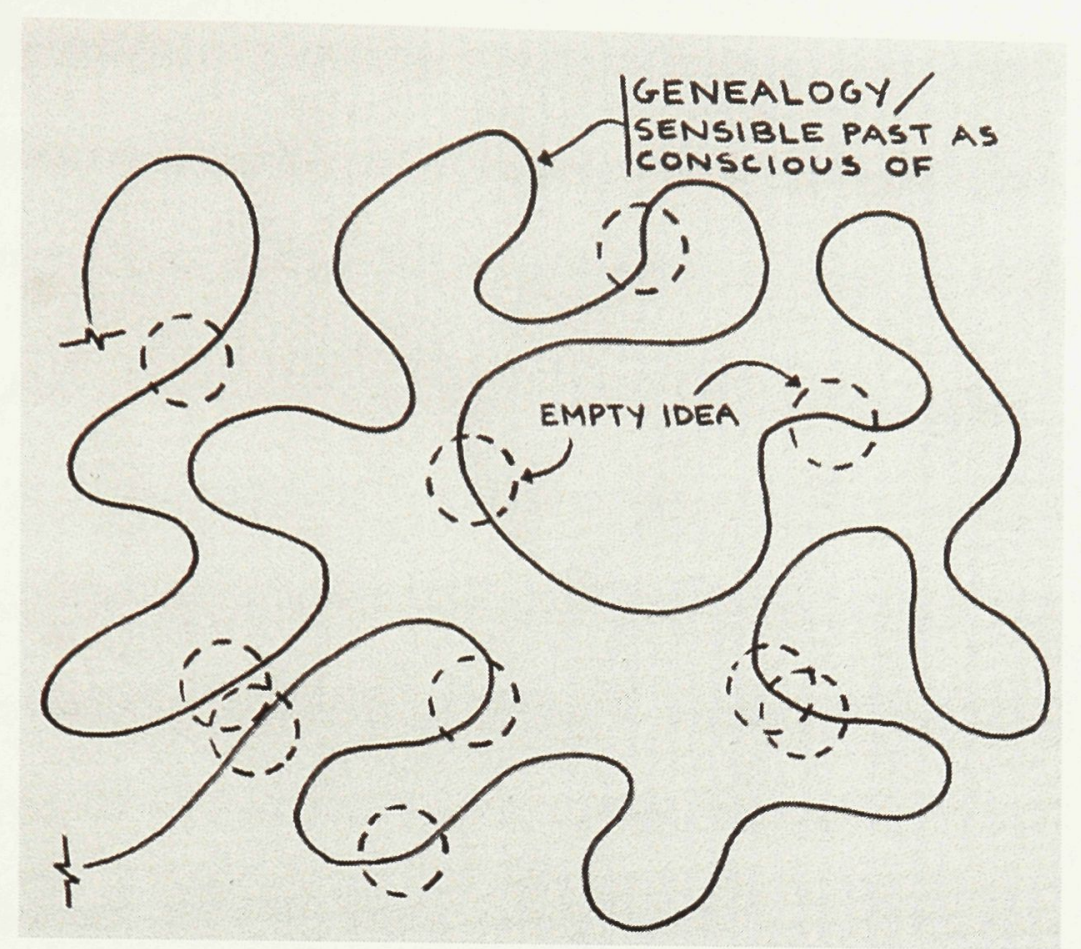

These Ideas (the conscious sensible past) are now external to one's self and thus external to the Subjective/Concept. The Ideas cannot act as 'signs' to be re-considered due to the absence of the subjective-self. Any attempt to do so would only consciously metaphorically-substitute one Idea for another Idea in an endless system of rationalization. The Idea, now external, can become metaphorically anything and nothing simultaneously.

In my exercise, the video, is the visualization of the system of related/unrelated - 'empty Ideas'. Here the Ideas (of given symbols) are not separate or equal any more, but rather disassociated and re-represented in and amongst themselves in an endless 'orgy' of Idea-ness. There is no over-arching Idea or 'concept' and there is no hegemony or reference to some 'thing'. The video can thus represent the function of all potential viewers gazing towards all potential objects simultaneously, and as such become, in and for itself an 'empty-Idea'. The 'objects' portrayed in the video cannot be perceived for/by the viewer-self 
because they are non-perceivable, non-signs (no logic, form, content, etc). The objects are only images (viewed for the video's own Being) which cannot be differentiated as true-objects. They exist together as video, as 'empty-Idea'.

Narrative is therefore a representation of a perceived sequence of events; non-narrative is the representation of perceiving as a sequence of events; and apostrophe is the representation of perceiving as a non-sequence (genealogy) of perceived events (Ideas) in/with no relation to a subject. The difference between 'sign as non-narrative' and 'sign as apostrophe' is that the 'sign' of apostrophe is not a sign but rather an 'empty-Idea'. As such, the non-narrative acts in relation to some thing and apostrophe is related to itself (self/poetreferential). As such, the poem/drawing/etc (as object) is not meant as a response or reflection on/for some thing but rather its presencing is for the lyrical. The poem is to be read as an entity (as itself - a non-referral presencing) in the time of the reader to 'experience' as an event. No 'meaning'/Truth was inserted into the poem (by poet) and no 'meaning'/Truth can be received from it (as non-sign), thus the Truth is/was its 'making of' as 'ends'.

Thus, the Exterior has seen its ultimate end. It exists in the realm of 'empty Idea'. When 'signs' are not presencing as/in the object, no externalization occurs (Objective, narrative) and no phenomenal exchange occurs (Subjective/Concept). The object is therefore not 'entered' (by relation to the sensible past) as 'sign' to be perceived, but exists in and for itself as the 'externally perceived': what constitutes the existence of the 'empty Idea'. The 
'making of' the object is thereby not relative to become/be a representation of/by/for the maker or the potential viewer but be total and complete as itself Real Being.

Language / Inter-Subjective / The Beginning

After 'sign as apostrophe' and the destruction of the 'sign' into the external-realm of 'empty Ideas', we arrive at 'sign as language'. The Objective/Universal is 'understood' through the use of language. All human communication and thoughts are constructed by/in language. It is the realm of the Exterior.

Language creates concrete 'truths' in the form of 'empty Ideas'. These abstract symbols give way to objective readings and deny subjective interpretations. In my 'Sign as Language' exercise, which is this document, I have illustrated the power of language. Its power is to sway personalinterpretations into an objective-singular mode of 'understanding'.

Within language there is a remedy for the re-emergence of the Subject from the Exterior. It is the intersubjective: a communication between subjective parties. Since language contains all previous signs; metaphor, narrative, apostrophe, the possibility for a subjective reading is given outside or at the limits of language (The 'sign as intersubjectivity' exercise is my thesis defense 
and the individual comments from all parties reading this document). And, thus, the thesis turns full-circle back to the beginning.

The intent of the thesis was to illustrate how 'external' modes of objective 'understanding' corrupts the subjective interpretation of an individual. This occurs within the given system of 'means to ends'. As I have proved, the system is itself that of the Exterior: a process away from the Subjective/Concept to the realm of external truths. To internalize the 'process', insomuch as it becomes a pure-act (event), one (the architect) must design for the 'ends'. This 'end' or 'designed' object, becomes a truely 'empty sign' when this occurs. As 'sign', it is for the viewer/inhabitor to give meaning/purpose/Truth for the 'act'. This 'interpretation' is formed by the 5 modes of externalization; metaphor, narrative, apostroph, language, intersubjective.

In each of the three exercises (metaphor, narrative, and apostrophe), I have compared an internal mode of interpreting to an exterior mode of realizing/rationalizing. In metaphor, I compared the internal metaphoric semblance/resemblance action of the Subjective/Concept to the exterior metaphoric system of 'processing'/means in relation to a 'concept' (overarching Idea as manifold). In narrative, I compared the exterior 'sign as narrative' (conveying a story) to the interior 'sign as narrative' (telling a story). In apostrophe, I compared the 'poet' (internal-solipsist) to the 'reader of poems' (exterior-empty Idea). Last I compared language (exterior) to intersubjectivity (interior) to arrive again at the dialetic that started off the exercises. 
Each of the exercises were 'set up' for you (the reader of this document) to view the images first and read the text second. This 'allowed' you to (potentially) interpret the images (by phenomenal exchange within your Subjective/Concept) before any meaning was imposed on from the outside (by the reading of this document).

One of the startling observations I gathered from doing this thesis and talking to others, was how quickly people 'gave up'/dis-regarded their own personal-interpretations for ones that were exterior to them. It became clear to me that Objective 'understanding' (through the use of dialogue-language) supplied the individual with a 'fact' that was easily considered Truth and quickly internalized/adapted for his use. This suggests that the tyrannical nature of the Universal is inescapable between two subjects in communication, but supports the existence of a 'difference' of original interpretation.

Architects can resist this Objective/Universal by creating architecture void of the system of 'means and ends'. This would deny all objective interpretations and give priority to the viewer/inhabitor. In this way, architecture would be free of classifications by movements, styles, methods, concepts, processes, etc, and could exist autonomus. Only by making (as end, sans means) can the maker's Subjective/Concept be revealed and endured. 


\section{End Notes}

${ }^{1}$ Adelmann, Frederick J., ed. The Quest for the Absolute. (Chestnut Hill: Boston College, 1966) 47-8

${ }^{2}$ Adelmann, Frederick J., ed. The Quest for the Absolute. (Chestnut Hill: Boston College, 1966) 49

${ }^{3}$ Adelmann, Frederick J., ed. The Quest for the Absolute. (Chestnut Hill: Boston College, 1966) 49

${ }^{4}$ Adelmann, Frederick J., ed. The Quest for the Absolute. (Chestnut Hill: Boston College, 1966) 52

${ }^{5}$ Adelmann, Frederick J., ed. The Quest for the Absolute. (Chestnut Hill: Boston College, 1966) 53

${ }^{6}$ Adelmann, Frederick J., ed. The Quest for the Absolute. (Chestnut Hill: Boston College, 1966) 54

${ }^{7}$ Adelmann, Frederick J., ed. The Quest for the Absolute. (Chestnut Hill: Boston College, 1966) 56

${ }^{8}$ Adelmann, Frederick J., ed. The Quest for the Absolute. (Chestnut Hill: Boston College, 1966) 57

${ }^{9}$ Adelmann, Frederick J., ed. The Quest for the Absolute. (Chestnut Hill: Boston College, 1966) 58

${ }^{10}$ Adelmann, Frederick J., ed. The Quest for the Absolute. (Chestnut Hill: Boston College, 1966) 60-1

${ }^{11}$ Adelmann, Frederick J., ed. The Quest for the Absolute. (Chestnut Hill: Boston College, 1966) 61

${ }^{12}$ Kojève, Alexandre. Introduction to the Reading of Hegel. 1947. Ed. Allan Bloom. Trans. James H. Nichols, Jr. (Ithaca, New York: Cornell UP, 1980) 124

${ }^{13}$ Kojève, Alexandre. Introduction to the Reading of Hegel. 1947. Ed. Allan Bloom. Trans. James H. Nichols, Jr. (Ithaca, New York: Cornell UP, 1980) 125

${ }^{14}$ Kojève, Alexandre. Introduction to the Reading of Hegel. 1947. Ed. Allan Bloom. Trans. James H. Nichols, Jr. (Ithaca, New York: Cornell UP, 1980) 127 
${ }^{15}$ Kojève, Alexandre. Introduction to the Reading of Hegel. 1947. Ed. Allan Bloom. Trans. James H. Nichols, Jr. (Ithaca, New York: Cornell UP, 1980) 129

${ }^{16}$ Kojève, Alexandre. Introduction to the Reading of Hegel. 1947. Ed. Allan Bloom. Trans. James H. Nichols, Jr. (Ithaca, New York: Cornell UP, 1980) 142-3

${ }^{17}$ Kojève, Alexandre. Introduction to the Reading of Hegel. 1947. Ed. Allan Bloom. Trans. James H. Nichols, Jr. (Ithaca, New York: Cornell UP, 1980) 130

${ }^{18}$ Lauer, Quentin. Hegel's Concept of God. (Albany: State U of New York P, 1982) 80

${ }^{19}$ Lauer, Quentin. Hegel's Concept of God. (Albany: State U of New York P, 1982) 81

${ }^{20}$ Lauer, Quentin. Hegel's Concept of God. (Albany: State U of New York P, 1982) 86

${ }^{21}$ Lauer, Quentin. Hegel's Concept of God. (Albany: State U of New York P, 1982) 83

${ }^{22}$ Kojève, Alexandre. Introduction to the Reading of Hegel. 1947. Ed. Allan Bloom. Trans. James H. Nichols, Jr. (Ithaca, New York: Cornell UP, 1980) 143

${ }^{23}$ Deleuze, Gilles. Francis Bacon: The Logic of Sensation. 1981. Trans. Daniel W. Smith. (Minneapolis: U of Minnesota Press, 2003) 32

${ }^{24}$ Deleuze, Gilles. Francis Bacon: The Logic of Sensation. 1981. Trans. Daniel W. Smith. (Minneapolis: U of Minnesota Press, 2003) 32

${ }^{25}$ Lyotard, Jean-Francois. The InHuman. Trans. Geoffrey Bennington and Rachel Bowlby. (Stanford: Stanford UP, 1991) 110-1

${ }^{26}$ Alphen, Ernst van. Francis Bacon and the Loss of Self. 1992. (London: Reaktion, 1998) 30

${ }^{27}$ Deleuze, Gilles. Francis Bacon: The Logic of Sensation. 1981. Trans. Daniel W. Smith. (Minneapolis: U of Minnesota Press, 2003) 36

${ }^{28}$ Deleuze, Gilles. Francis Bacon: The Logic of Sensation. 1981. Trans. Daniel W. Smith. (Minneapolis: U of Minnesota Press, 2003) 28 
${ }^{29}$ Frie, Roger. Subjectivity and Intersubjectivity In Modern Philosophy and Psychoanalysis: A study of Sartre, Binwanger, Lacan, and Habermas. (New York: Rowman \& Littlefield Publishers Inc., 1997) 4

${ }^{30}$ Lacan, Jacques. Écrits: A Selection. New York: (W.W. Norton \& Company, 1977) 1

${ }^{31}$ Lacan, Jacques. Écrits: A Selection. New York: (W.W. Norton \& Company, 1977) 1

${ }^{32}$ Lacan, Jacques. Écrits: A Selection. New York: (W.W. Norton \& Company, 1977) 1

${ }^{33}$ Bal, Mieke. Narratology: Introduction to the Theory of Narrative. Trans. Christine van Boheemen. (Toronto: U of Toronto P, 1985) 5

${ }^{34}$ Bal, Mieke. Narratology: Introduction to the Theory of Narrative. Trans. Christine van Boheemen. (Toronto: U of Toronto P, 1985) 104

${ }^{35}$ Bal, Mieke. Narratology: Introduction to the Theory of Narrative. Trans. Christine van Boheemen. (Toronto: U of Toronto P, 1985) 104

${ }^{36}$ Bortolussi, Marisa and Peter Dixon. Psychonarratology: Foundations for the Empirical Study of Literary Response. (Cambridge: Cambridge UP, 2003) 170

${ }^{37}$ Alphen, Ernst van. Francis Bacon and the Loss of Self. 1992. (London: Reaktion, 1998) 30

${ }^{38}$ Alphen, Ernst van. Francis Bacon and the Loss of Self. 1992. (London: Reaktion, 1998) 28

${ }^{39}$ Alphen, Ernst van. Francis Bacon and the Loss of Self. 1992. (London: Reaktion, 1998) 45

${ }^{40}$ Alphen, Ernst van. Francis Bacon and the Loss of Self. 1992. (London: Reaktion, 1998) 89

${ }^{41}$ Culler, Jonathan. The Pursuit of Signs: Semiotics, Literature, Deconstruction. (New York: Cornell UP, 1981) 135

${ }^{42}$ Culler, Jonathan. The Pursuit of Signs: Semiotics, Literature, Deconstruction. (New York: Cornell UP, 1981) 138 
${ }^{43}$ Culler, Jonathan. The Pursuit of Signs: Semiotics, Literature, Deconstruction. (New York: Cornell UP, 1981) 139

${ }^{44}$ Yeats, W.B. 'Among School Children,' Varoirum edition of the poems of W.B. Yeats. (London: Macmillan, 1940) 445-6

${ }^{45}$ Culler, Jonathan. The Pursuit of Signs: Semiotics, Literature, Deconstruction. (New York: Cornell UP, 1981) 137

${ }^{46}$ Culler, Jonathan. The Pursuit of Signs: Semiotics, Literature, Deconstruction. (New York: Cornell UP, 1981) 146

${ }^{47}$ Culler, Jonathan. The Pursuit of Signs: Semiotics, Literature, Deconstruction. (New York: Cornell UP, 1981) 142

${ }^{48}$ Culler, Jonathan. The Pursuit of Signs: Semiotics, Literature, Deconstruction. (New York: Cornell UP, 1981) 146

${ }^{49}$ Culler, Jonathan. The Pursuit of Signs: Semiotics, Literature, Deconstruction. (New York: Cornell UP, 1981) 149

${ }^{50}$ Culler, Jonathan. The Pursuit of Signs: Semiotics, Literature, Deconstruction. (New York: Cornell UP, 1981) 148

${ }^{51}$ Culler, Jonathan. The Pursuit of Signs: Semiotics, Literature, Deconstruction. (New York: Cornell UP, 1981) 148

${ }^{52}$ Culler, Jonathan. The Pursuit of Signs: Semiotics, Literature, Deconstruction. (New York: Cornell UP, 1981) 150 


\section{Bibliography}

Adelmann, Frederick J., ed. The Quest for the Absolute. Chestnut Hill: Boston College, 1966.

Alphen, Ernst van. Francis Bacon and the Loss of Self. 1992. London: Reaktion, 1998.

Arendt, Hannah. The Human Condition. 1958. Introd. Margaret Canovan. 2nd ed. Chicago: U of Chicago P, 1998.

Bal, Mieke. Narratology: Introduction to the Theory of Narrative. Trans. Christine van Boheemen. Toronto: U of Toronto P, 1985.

Bortolussi, Marisa and Peter Dixon. Psychonarratology: Foundations for the Empirical Study of Literary Response. Cambridge: Cambridge UP, 2003.

Cicovacki, Predrag. Between Truth and Illusion: Kant at the Crossroads of Modernity. Lanham, Maryland: Rowman, 2002.

Culler, Jonathan. The Pursuit of Signs: Semiotics, Literature, Deconstruction. New York: Cornell UP, 1981.

Darby, Tom. The Feast: Meditations of Politics and Time. 1982. Toronto: U of Toronto P, 1990.

Deleuze, Gilles. Francis Bacon: The Logic of Sensation. 1981. Trans. Daniel W. Smith. Minneapolis: U of Minnesota Press, 2003.

Ficacci, Luigi. Francis Bacon 1909-1992. Köln, Germany: Taschen GmbH, 2003.

Fireman, Gary D., Ted E. McVay, Jr., and Owen J. Flanagan, eds. Narrative and Consciousness: Literature, Psychology, and the Brain. New York: Oxford UP, 2003.

Frie, Roger. Subjectivity and Intersubjectivity In Modern Philosophy and Psychoanalysis: A study of Sartre, Binwanger, Lacan, and Habermas. New York: Rowman \& Littlefield Publishers Inc., 1997.

Genette, Gérard. Narrative Discourse Revisited. Trans. Jane E. Lewin. Ithaca, New York: Cornell UP, 1988.

Heidegger, Martin. Hegel's Concept of Experience. New York: 1817-Harper, 1970. 
---. The Question of Modernity and Other Essays. Trans. William Lovitt. New York: Harper, 1977.

James, William. The Principles of Psychology. Vol. 2. London: LondonMacmillan, 1890.

Kojève, Alexandre. Introduction to the Reading of Hegel. 1947. Ed. Allan Bloom. Trans. James H. Nichols, Jr. Ithaca, New York: Cornell UP, 1980.

Kuhn, Thomas S. The Structure of Scientific Revolutions. 3rd ed. Chicago: U of Chicago P, 1996.

Lacan, Jacques. Écrits: A Selection. New York: W.W. Norton \& Company, 1977.

Lauer, Quentin. Hegel's Concept of God. Albany: State U of New York P, 1982.

Lyotard, Jean-Francois. The InHuman. Trans. Geoffrey Bennington and Rachel Bowlby. Stanford: Stanford UP, 1991.

Pillow, Kirk. Sublime Understanding: Aesthetic Reflection in Kant and Hegel. Cambridge: MIT P, 2000.

Rousseau, Jean-Jacques. The Social Contract. Trans. Maurice Cranston. London: Penguin 1968.

Russell, John. Francis Bacon. London: Thames and Hudson, 1971.

Thomas Aquinas. On the Eternity of the World. Trans. Lottie H. Kendzierski and Cyril Vollert. Milwaukee: Marquette UP, 1964.

---. Truth: Questions I-IX. Trans. Robert W. Mulligan. Vol. 1. Chicago: Henry Regnery, 1952.

---. Truth: Questions X-XX. Trans. James V. McGlynn. Vol. 2. Chicago: Henry Regnery, 1952.

--- Truth: Questions XXI-XXIX. Trans. Robert W. Schmidt. Vol. 3. Chicago: Henry Regnery, 1954.

Verene, Donald P. Vico's Science of Imagination. Ithaca, New York: Cornell UP, 1981.

Yeats, W.B. Varoirum edition of the poems of W.B. Yeats. London: Macmillan, 1940. 
Sign as Intersubjective 